\title{
Natural products for infectious microbes and diseases: an overview of sources, compounds, and chemical diversities
}

\author{
Lu Luo ${ }^{1}$, Jun Yang ${ }^{1}$, Cheng Wang ${ }^{2}$, Jie Wu ${ }^{1}$, Yafang $\mathrm{Li}^{3}, \mathrm{Xu}_{7} \mathrm{Zhang}^{4}{ }^{4}$, Hui $\mathrm{Li}^{5}$, Hui Zhang ${ }^{6}$, \\ Yumei Zhou ${ }^{7}$, Aiping Lu ${ }^{8} \&$ Shilin Chen ${ }^{1}$ \\ ${ }^{1}$ Institute of Chinese Materia Medica, China Academy of Chinese Medical Sciences, Beijing 100700, China; \\ ${ }^{2}$ Institute of Basic Medical Sciences, Chinese Academy of Medical Sciences \& Peking Union Medical College, Beijing 100006, China; \\ ${ }^{3}$ Institute of Hematology \& Blood Diseases Hospital, Chinese Academy of Medical Sciences \& Peking Union Medical College, \\ Tianjin 300020, China, \\ ${ }^{4}$ weMED Health, Houston 77054, USA; \\ ${ }^{5}$ Institute of Botany, Chinese Academy of Sciences, Beijing 100093, China; \\ ${ }^{6}$ Akupunktur Akademiet, Aabyhoej 8230, Denmark; \\ ${ }^{7}$ The Fourth Clinical Medical College of Guangzhou University of Chinese Medicine, Guangzhou 518033, China; \\ ${ }^{8}$ School of Chinese Medicine, Hong Kong Baptist University, Hong Kong 999077, China
}

Received May 21, 2021; accepted July 27, 2021; published online October 21, 2021

\begin{abstract}
As coronavirus disease 2019 (COVID-19) threatens human health globally, infectious disorders have become one of the most challenging problem for the medical community. Natural products (NP) have been a prolific source of antimicrobial agents with widely divergent structures and a range of vast biological activities. A dataset comprising 618 articles, including 646 NP-based compounds from 672 species of natural sources with biological activities against 21 infectious pathogens from five categories, was assembled through manual selection of published articles. These data were used to identify 268 NP-based compounds classified into ten groups, which were used for network pharmacology analysis to capture the most promising lead-compounds such as agelasine D, dicumarol, dihydroartemisinin and pyridomycin. The distribution of maximum Tanimoto scores indicated that compounds which inhibited parasites exhibited low diversity, whereas the chemistries inhibiting bacteria, fungi, and viruses showed more structural diversity. A total of 331 species of medicinal plants with compounds exhibiting antimicrobial activities were selected to classify the family sources. The family Asteraceae possesses various compounds against $C$. neoformans, the family Anacardiaceae has compounds against Salmonella typhi, the family Cucurbitacea against the human immunodeficiency virus (HIV), and the family Ancistrocladaceae against Plasmodium. This review summarizes currently available data on NPbased antimicrobials against refractory infections to provide information for further discovery of drugs and synthetic strategies for anti-infectious agents.
\end{abstract}

natural product, infectious pathogen, drug discovery, drug development, in silico analysis

Citation: Luo, L., Yang, J., Wang, C., Wu, J., Li, Y., Zhang, X., Li, H., Zhang, H., Zhou, Y., Lu, A., et al. (2022). Natural products for infectious microbes and diseases: an overview of sources, compounds, and chemical diversities. Sci China Life Sci 65, 1123-1145. https://doi.org/10.1007/s11427-020-1959-5

\section{Introduction}

Infectious diseases are a significant challenge to public

*Corresponding author (email: slchen@icmm.ac.cn) health, producing the second highest number of deaths from disease globally. Natural products (NP), which have properties evolutionarily optimized for different biological functions (Atanasov et al., 2015), have been a prolific source of antimicrobial agents with widely divergent structures and 
biological activities (Atanasov et al., 2015). With the advent of combinatorial chemistry and high-throughput screening (HTS) over the last few decades (Atanasov et al., 2015), there has been a surge in the identification of new molecular architectures and their precise mechanism of action (MOA), including an ever-increasing number of NPs (Teijaro et al., 2018). Currently, approximately $60 \%$ of approved smallmolecule medicines are related to NPs, and $69 \%$ of all antibacterial agents are derived from NPs (Zuo et al., 2012). Antimalarial drugs such as quinine and artemisinin are examples of widely used, effective drugs derived from NPs (Chen et al., 2020).

The plant kingdom serves as a unique resource for antimicrobial compounds (Atanasov et al., 2015). The first written records of plant medicine date from 2,600 BC, in Egypt (Cragg and Newman, 2013). Similar to traditional Chinese medicine (TCM), which had systematically been applied for over two thousand years (Winder, 1988), the documentation of the Indian Ayurveda system dates back to the first millennium BC (Patwardhan, 2005). The herbal medicine of Europe is largely derived from Greek and Roman medicine. The Arabs preserved many Greco-Roman medical books during the Dark and Middle Ages in the fifth to twelfth centuries (Cragg and Newman, 2013). The search for antimicrobial agents, in particular, has largely been focused on the exploration of NPs, as almost all the antibiotic scaffolds were derived from natural sources (Newman and Cragg, 2016). It has been estimated that 350 agents, including NPs, semi-synthetic antibiotics, and synthetic chemicals, have so far reached the world market as antimicrobials (Salam and Quave, 2018). The successful discovery of artemisinin was due to the exploration of antique Chinese herbal medicine books.

The adaptive capability of plant eukaryotic antibiotics is still uncharted territory, although these antibiotics have historically been used against viral, bacterial, fungal, and parasitic infections (Dvorkin-Camiel and Whelan, 2008). Microorganisms are a prolific source of structurally diverse bioactive medicines. The discovery of penicillin from $\mathrm{Pe}$ nicillium notatum by Alexander Fleming in 1928 marked a significant shift from plants to microorganisms as a source of natural antimicrobial agents (Atanasov et al., 2015). During the following decades, various bioactive NPs, including quinine, caffeine, nicotine, codeine, atropine, colchicine, cocaine, and capsaicin, were isolated from their natural sources (Atanasov et al., 2015). The twentieth century witnessed the development of compounds with apparently miraculous properties, mainly in the form of antibiotics (Dvorkin-Camiel and Whelan, 2008). Many of these drugs were developed from diverse groups of fungi, in which twothirds of antibiotics are produced by members of the bacterial order actinomycetales (Cragg and Newman, 2013). The marine environment is another rich source of bioactive compounds, many of which belong to totally novel chemical classes, not previously discovered in terrestrial sources (Akram et al., 2018). During the decade from 1977 to 1987, about 2,500 new metabolites were reported from various marine organisms, and in 2010 alone, 1,003 new compounds were published (Blunt et al., 2012).

NPs continue to serve as essential sources of chemical entities, supporting drug discovery for infectious diseases. A dataset comprising a relatively complete list of NPs which have been used against five categories of major infectious pathogens has been assembled through a manual selection of published articles (Pubmed, Google Scholar, Web of Science, and CNKI). In this review we use this resource to discover NP-based antimicrobials which may be active against refractory infections, attempt to predict the future for drug discovery in this arena, and endeavor to spark the curiosity of investigators who might enter this fascinating, complex landscape of NPs and their interactions with infection.

\section{Classifications of infectious pathologies in conven- tional and traditional medicines}

When infectious pathogens enter the human body, non-specific and specific immunity protects the body from the attack (Reller et al., 2001). Phagocytosis, a typical non-specific mechanism of protection, induced by neutrophils and macrophages, occurs. The remaining pathogens are cleared as completely as possible by antibody-mediated humoral immunity and cell-mediated immunity, with the help of other immune molecules (Reller et al., 2001). Immune reactions fall into two opposite yet cooperative systems, just like the Yin and Yang conception from Daoism in the basic theory of TCM: immune initiation and response (Yang), participated by activators and effectors such as $\mathrm{T}$ cells $\left(\mathrm{Th}_{1}, \mathrm{Th}_{17}\right), \mathrm{B}$ cells, $\mathrm{DC}, \mathrm{M} \varphi$, NK cells, NKG2D, and IFN- $\gamma$; and immune regulation and tolerance (Yin), managed by regulators and controllers such as IL-10, NKG2A, $\mathrm{T}_{\text {reg }}, \mathrm{Th} 2, \mathrm{~B}_{\text {reg }}, \mathrm{DC}_{\text {reg }}$, and M2. The detailed strategy of the human immune system against pathogens changes with the characteristics of each pathogen, from virus to parasite. The classification of infectious pathologies in conventional medicine is pathogenoriented, and usually includes viruses, bacteria, fungus, parasites, and chlamydia and mycoplasmas. We selected and summarized potential NP candidates for severe and refractory pathologies caused by infectious pathogens from these five categories.

From the perspective of TCM, infectious pathologies occur as a result of macroclimate or physical changes, leading to imbalance of the Yin-Yang of the body, followed by the development of various symptoms. Infections are caused by an external pathogenic attack-pestilent Qi or evil Qi-due to 
climatic or environmental changes. A weakened immune system results in disease arising from the battle between healthy Qi (immunity) and pathogenic Qi (pathogens) (Luo et al., 2020). The former, functioning as a defending barrier, basically consists of four layers, from the exterior to the interior: defensive Qi, Qi, nutrient Qi, and Blood. Therefore in TCM, the classification of infections is always symptomoriented. As mentioned in Volume Plain Questions, Chapter Discussion on Acupuncture, Inner Cannon of Yellow Emperor (Huang Di Nei Jing), "all the five categories of pestilences are contagious in a similar way with similar symptoms" (Yao, 2010). Here "five categories of pestilences" refer to cold pestilence (with symptoms manifesting cold), warm pestilence (with symptoms manifesting heat), larynx infection, infectious dysentery, and parasite infection, manifested by different syndromes. The reaction between antigen and antibody, or evil Qi and healthy Qi, induced by external attack, happens to correspond well in the two systems of medicines (Ma, 1981). The discovery of artemisinin is one typical example from the Chinese herbal database, built based on thousands of years of clinical experience (Figure 1).

\section{Data sources and mining of NP against five cate- gories of infectious pathogens}

Both English databases, including PubMed (Canese and Weis, 2013), Google Scholar (Vine, 2006), and Web of Science (Analytics, 2017), and Chinese databases, including CNKI (Xia et al., 2008) and Wanfang (Wang and Shi, 2012) were searched to collect currently available literature. We conducted activity-based selection on NPs against 21 infectious pathogens covering five categories: viruses (hepatitis B virus (HBV), influenza virus (IAV), herpes simplex virus (HSV), human immunodeficiency virus (HIV), severe acute respiratory syndrome coronavirus (SARS-CoV), Middle East respiratory syndrome coronavirus (MERS-CoV), and severe acute respiratory syndrome coronavirus 2 (SARS-CoV-2); bacteria (Salmonella typhi, Shigella, Mycobacterium tuberculosis, methicillin-resistant staphylococcus aureus (MRSA), Streptococcus pneumonia, and Helicobacter pylori); fungi (Cryptococcus neoformans and Malassezia furfur); parasites (Plasmodium, Schistosoma, Trichomonas vaginalis); and other categories (Leptospira, Treponema Pallidum, and Prion). All included articles were classified into five levels of evidence regarding the robustness of data and experiments conducted. Articles containing only in vitro experiments, conducted or primarily screened by molecular docking, were considered Level One evidence; those with in vitro experiments plus animal model testing or the identification of specific molecular interactions were considered Level Two; those involving signal pathways were considered Level Three; those involving examination of molecular effects by gene knockdown were considered Level Four; and those including molecular docking or other experiments to test the direct binding of the target based on pharmacodynamics and mechanism studies, were considered Level Five.

A total of 618 articles were collected. These articles included 646 NP-based compounds, from 672 natural sources, with biological activities against 21 pathogenic organisms, from five different categories. Of the articles, 91.59\% (566) reported in vitro experiments, $2.75 \%$ (17) reported a combination of in vivo and in vitro research, 2.10\% (13) were in vivo studies, $1.29 \%$ (8) were in silico studies, and $0.16 \%$ (1) was an in vitro study with in silico screening. With respect to level of evidence, $85.11 \%$ (526) of the studies available were categorized as providing level one evidence, $11.33 \%$ (70) provided level two evidence, $2.75 \%$ (17) had level-three evidence, $0.16 \%$ (1) had level-four evidence, and $0.64 \%$ (4) provided level-five evidence, indicating that most of the current studies into NPs are still at the preliminary stage, and the MOA and specific targets should be a focus of further exploration (Supplementary materials in Supporting Information).

We selected data from some of the most representative pathogens from each category for further discussion.

\section{NPs against viruses}

There are numerous, potentially useful, NPs to be evaluated and exploited for therapeutic applications against different virus families (Kitazato et al., 2007). Three major mechanisms of inhibition of $\mathrm{HBV}$ by compounds from natural sources have been reported: the inhibition of HBV covalently closed circular DNA (cccDNA) (Wang, 2008), regulation of $\mathrm{HBV}$ replication, and inhabitation of $\mathrm{HBV}$ replication by modifying JNK/MIAPK signal pathway. Studies have shown that some effective components from medicinal plants can inhibit the replication of HBV DNA as well as cccDNA (Su et al., 2017). Epigallocatechin gallate, a catechin compound extracted from green tea, has an antiviral effect on the HBV tolerant cell line Hep G2.117, and has an inhibitory effect on pre-core mRNA, cccDNA, and replication intermediate DNA, which are involved in HBV expression (Wang, 2008).

Treatments for acquired immune deficiency syndrome (AIDS) generally fall into the categories of HIV suppression or HIV reactivation (Cary and Peterlin, 2018). A promising area of research involves a deeper understanding of the identification of drug targets which prevent HIV transcription is the goal to achieve a functional cure (Chang et al., 2011; Deeks, 2012). These HIV reverse transcriptase inhibitors include biflavonoids from Rhus succedanea (Lin et al., 1997), michellamines from Ancistrocladus korupensis (Boyd et al., 1994), and lanostane-type triterpenes from 


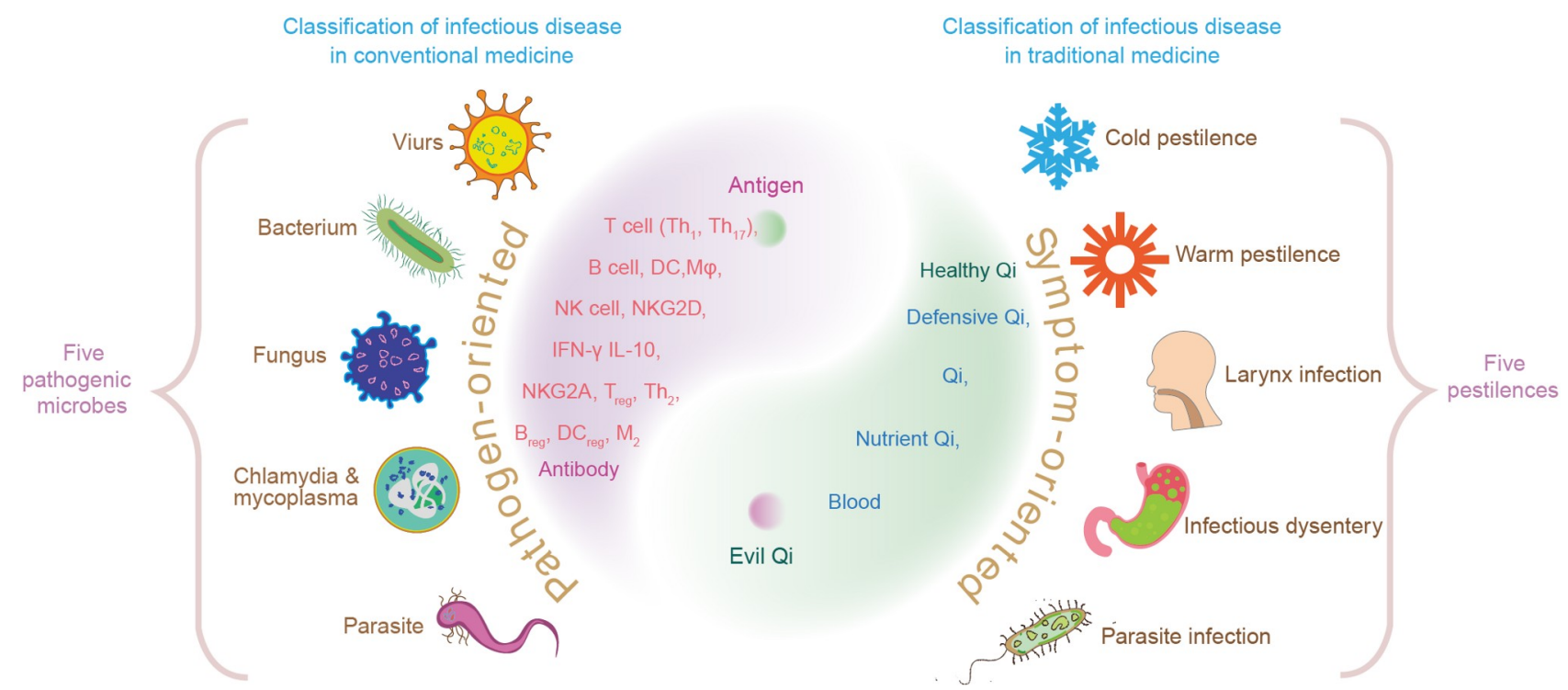

Figure 1 Classification of infectious diseases in conventional and traditional medicines. Left panel, The classification of infectious pathologies in conventional medicine is pathogen-oriented, including five categories: viruses, bacteria, fungi, parasites, and chlamydia and mycoplasmas. The immune reactions could be generally elucidated by two opposite yet cooperative systems, just like the Yin and Yang conception from Daoism in the basic theory of TCM: immune initiation and response (Yang), involving activators and effectors such as T cells $\left(\mathrm{Th}_{1}, \mathrm{Th}_{17}\right), \mathrm{B}$ cells, DC, M $\varphi$, NK cells, NKG2D, and IFN- $\gamma$; and immune regulation and tolerance (Yin), managed by regulators and controllers such as IL-10, NKG2A, $\mathrm{T}_{\text {reg }}, \mathrm{Th}_{2}$, $\mathrm{B}_{\mathrm{reg}}, \mathrm{DC}$ reg, and M2. Right panel, From the perspective of traditional medicine, the classification of infections is always symptom-oriented. The diseases occur due to imbalance between healthy Qi (immunity) and pathogenic Qi (pathogen). The Inner Cannon of Yellow Emperor (Huang Di Nei Jing) classified five categories of pestilences, cold pestilence, warm pestilence, larynx infection, infectious dysentery, and parasite infection, manifested by different syndromes. The recovery from diseases depends on the battle between healthy Qi (immunity) and pathogenic Qi (pathogen). The former, functioning as a defending barrier, basically consists of four layers from the exterior to the interior: defensive Qi, Qi, nutrient Qi, and Blood.

Polyalthia suberosa (Li et al., 1993). Three of the active compounds identified are known to be HIV integrase inhibitors: flavonoid gallate ester from Acer okamotaanum (Kim et al., 1998), and dicaffeoylquinic acids from Achyrocline satureioides (Zhu et al., 1999). Some active compounds were found to be HIV protease inhibitors: watersoluble lignins from Inonotus obliquus (Ichimura et al., 1998), uvaol and ursolic acid from Crataegus pinatifida (Min et al., 1999), and maslinic acid from Geum japonicum (Xu et al., 1996; Chisembu and Hedimbi, 2009).

At present, no preventive vaccines or established antiviral therapies are available for coronaviruses (Sohrabi et al., 2020). However, several synthetic compounds have shown promise, including hydroxychloroquine and choloroquine phosphate (Cortegiani et al., 2020), which act through several mechanisms, including alkalinization of the host cell phagolysosomes. Despite the short time since the emergence of SARS-CoV-2 several studies have reported on the use of computer modeling for screening for the inhibition of this virus (Liu and Zhou, 2005). Typically, these models determine the free binding of energy between a ligand and a receptor, with a lower free binding energy indicating a stronger bond between the ligand and the receptor (Lung et al., 2020). Several researchers have utilized virtual computer docking models to screen for potential compounds that could bind to and inhibit key proteins present in SARS-CoV (Liu and Zhou, 2005), highlighting the potential antiviral activity of compounds such as sabadinine and aurantiamide acetate. Only a handful of studies have investigated the potential of NPs as therapeutic agents against MERS-CoV (Richardson et al., 2020). Silvestrol, a phytochemical from Aglaia sp., has been found to be a potent inhibitor of MERS-CoV replication $\left(\mathrm{EC}_{50}\right.$ of $1.3 \mathrm{nmol} \mathrm{L}{ }^{-1}$ ) (Müller et al., 2018). Some promising compounds for the treatments of coronavirus include scutellarein, Silvestro L, tryptanthrin, saikosaponin $\mathrm{B}_{2}$, griffithsin, lycorine, and polyphenolics (Müller et al., 2018).

\section{NPs against bacteria}

NPs have played a vital role in the development of antimicrobial drugs, such as discovering of rifamycins (1957), quinolone (1962), trimethoprim (1968), oxazolidinone (2000), and antibacterial lipopeptides (2003), polyketides, non-ribosomal peptides, and aminoglycosides (Butler, 2005; Pham et al., 2019). Staphylococcus aureus infection is the leading cause of hospital-acquired pneumonia and infection of surgical wounds (Ambé et al., 2015). MRSA tends to be multi-drug resistant (MDR), exhibiting resistance not only to $\beta$-lactam antibiotics but also to a variety of antibiotic classes. Most of the active extracts contained tannins, (poly)phenols (including flavonoids, lignans and coumarins), terpenoids or alkaloids, which have been previously reported to be active compounds against MRSA. The considerable antibacterial activity against MRSA of grape seed extract (Vitis vinifera L; Vitaceae), 
which is rich in potent antioxidant polyphenolics, signified a major advancement in the treatment of MRSA diseases (AlMousawi et al., 2020). Aqueous extract of Enantia polycarpa, a tropical plant of the Annonaceae family (Ambé et al., 2015), had bactericidal activity against $75 \%$ of MRSA strains tested. It had minimum inhibitory concentration (MIC) and minimum bactericidal concentration (MBC) values of 3.125 and $12.5 \mathrm{mg} \mathrm{mL}^{-1}$, respectively. Phytochemical analysis revealed the presence of saponins, alkaloids, and tannins in an aqueous extract (Ambé et al., 2015).

\section{NPs against fungi}

Many of the antibiotics currently used for the treatment of infections come from fungi. Fungi imperfecti, or Penicillium, and Cephalosporium were the two of the first fungi identified as having antibiotic activity (Dvorkin-Camiel and Whelan, 2008). There are five groups of antifungal agents approved for human consumption: the azoles, the polyenes, the echinocandins, the allylamines, and the antimetabolites (Howard et al., 2020).

Cryptococcal meningitis (CM) is a vital mycosis caused by Cryptococcus neoformans and Cryptococcus gattii, which leads to over one million cases and 600,000 deaths per year (Sloan and Parris, 2014; Liu et al., 2012; Park et al., 2009). Cryptococcosis primarily manifests after $C$. neoformans enters and colonizes the lungs (Saag et al., 2000; Samie et al., 2019). The successful colonization of the host by $C$. neoformans is attributed to its approximately 150 reported virulence factors (Malachowski et al., 2016). Pelargonium sidoides extract has been found to retain its antifungal activity for up to four years after preparation. The yeast cell wall and membrane are its first line of defense against its extracellular environment (Bahn et al., 2005). C. neoformans enlarges its capsule through distal growth by releasing and attaching capsular components stored within secreted vesicles to the outer edge of the capsule (Zaragoza et al., 2006). Preliminary investigation of the antifungal mechanism revealed that the active compounds induced apoptosis of $C$. neoformans cells and arrested the cell cycle at the G1/S phase. Berberine, a protoberberine-type isoquinoline alkaloid isolated from Berberis aquifolium, Berberis vulgaris, Berberis aristata, and Hydrastis canadensis, has been shown to have broad antibacterial and antifungal activity. Berberine causes damage to the cell membrane, and the possible impairment of cell function. Berberine may affect mitochondrial respiratory function, causing the breakdown of $\Delta \Psi \mathrm{m}$ and a lack of accumulation of rhodamine 123 in the mitochondria (Ludovico et al., 2001).

\section{NPs against parasites}

Schistosomiasis, caused by flatworms of the genus Schisto- soma, is one of the most neglected tropical diseases (Veras et al., 2012). Schistosoma mansoni is the major etiological agent of human schistosomiasis, and praziquantel (PZQ) is the only drug available to treat this neglected disease. There is therefore an urgent need for new drugs. Recent studies have indicated that extracts from Piper aduncum (Piperaceae) are active against adult worms of $S$. mansoni. Extracts of cardamonin from P. aduncum caused tegumental alterations, and reduction of oviposition and motor activity in worms of S. mansoni. Another two compounds, luteolin and (3R,6R)-linalool oxide acetate, showed anthelmintic activity against $S$. mansoni $\left(\mathrm{IC}_{50}\right.$ range from 5.8 to $\left.36.9 \mu \mathrm{g} \mathrm{mL} L^{-1}\right)$. Luteolin induced tegumental damage in $S$. mansoni (Wangchuk et al., 2016). A bioguided phytochemical study identified 2-methoxy-6-pentyl-benzoquinone, also known as Primin, as the major bioactive metabolite producing toxicity against adult S. mansoni worms (Viegas et al., 2017). An in vivo study showed that the methanolic fraction of Clerodendrum umbellatum reduced the hepatosplenomegaly induced by infection with $S$. mansoni, and prevented the elevated malondialdehyde (MDA) level induced by the infection, while producing a significant increase in catalase activity and glutathione levels. Phytochemical analysis of an aqueous fraction from C. umbellatum leaf extract revealed the presence of alkaloids, flavonoids, cardiac glycosides, phenols, saponins, tannins, and terpenoids (Jatsa et al., 2015). Extract of Ramalina aspera shows a cercaricidal effect on $S$. mansoni at a concentration of $5.0 \mu \mathrm{g} \mathrm{mL}^{-1}$, with effective molluscicidal activity against the embryos and adult snails of the species B. glabrata and cercariae of $S$. mansoni. It could be a promising molluscicidal and cercaricidal agent (Silva et al., 2019).

\section{NPs against other infectious pathogens}

Prions are the infectious agents that cause neurodegenerative diseases, known as prion diseases or transmissible spongiform encephalopathies (TSEs). These diseases include Creutzfeldt-Jakob disease (CJD), kuru, fatal familial insomnia, scrapie, and bovine spongiform encephalopathy (Aguzzi and Liu, 2017). A variety of anti-prion compounds, including pentosane polysulfate, polyamines, amantadine, astemizole, dextran sulfate, Congo red, suramin, rapamycin, and quinacrine have been reported to bind to the prion protein $\operatorname{PrP}^{\mathrm{C}}$, acting as chemical chaperones to reduce the accumulation of $\operatorname{PrP}^{\mathrm{Sc}}$ in cell culture (Ishibashi et al., 2016; Imberdis et al., 2016), with specific binding to the hotspot region of $\operatorname{PrP}^{\mathrm{C}}$ (Ferreira et al., 2014). However, most of the compounds which were active in vitro have failed in vivo ( $\mathrm{Li}$ and Weng, 2017). Two novel and potent NPs, BNP-03 $((1 \mathrm{~s}, 3 \mathrm{R}, 4 \mathrm{r}, 5 \mathrm{~S})-3,5-b i s(((\mathrm{E})-3-(3,4-d i h y d r o x y p h e n y l) a c r y-$ loyl)oxy)-1,4-dihydroxycyclohexane-1-carboxylic acid) and BNP-08 ((1R,3R,4R,5S)-1,3-bis(((E)-3-(3,4-dihydrox- 
yphenyl)acryloyl)oxy)-4,5-dihydroxycyclohexane-1-carboxylic acid) selected from self-constructed dabase by Choi et al. (2018), showed inhibitory effects, reducing $\operatorname{PrP}^{\mathrm{Sc}}$ signals in a standard scrapie cell assay (Klöhn et al., 2003). Several naturally occurring polyphenols, phenothiazines, antihistamines, statins, and antimalarial compounds are potent prion inhibitors. Several of the new $\mathrm{PrP}^{\mathrm{Sc}}$ inhibitors cross the blood-brain barrier, and thus have the potential to be active after TSE infection reaches the brain (Kocisko et al., 2003). In one study, a total of 500 marine invertebrate extracts were searched for yeast-prion inhibiting extracts. Five compounds exhibiting detectable anti-prion activities were isolated: aplysamine-1, aplysamine-2, purealidine-Q, 3,5dibromoverongiaquinol, and 3,5-dibromoverongiaquinol dimethyl ketal (Jennings et al., 2018). All active compounds identified in the extract of the sponge Suberea ianthelliformis contained an ethylaminodibromophenyl (EADP) moiety, and were identified as potent inhibitors of yeast prions (Hamann et al., 1993; Tsukamoto et al., 1996). The EADP structure class may serve as a useful lead for the future development and design of novel and improved anti-prion therapeutics (Tilvi et al., 2004; Ishibashi et al., 1991). The $\mathrm{H}_{3}$ receptor, ApoE and AChE have all been identified as potential targets for treating various neurodegenerative diseases (Morisset et al., 2000; Torrent et al., 2015).

From the data collected, several different mechanisms appear to be involved in treating infectious diseases by natural products. Anti-microorganism mechanisms include enzyme inhibition and the disruption of the permeability or integrity of the membranes of microorganisms. The former acts through: (i) inhibition of integrase, reverse transcriptase, or RNA polymerase, such as treatments for HIV and IAV infection (Wang et al., 2018; Panthong et al., 2015; HuertaReyes et al., 2004), which inhibit nucleic acid (DNA/RNA) replication of viruses in host cells; (ii) inhibition of essential enzymes for viral propagation like ATPase/MERS-3CLpro enzyme/SARS-3CLpro (Yu et al., 2012; Jo et al., 2019; Su et al., 2020); (iii) inhibition of the functional enzymes of microbes to reduce their pathogenicity, like GlmU/InhA/iNOS and COX-2 (Han et al., 2019; Hartkoorn et al., 2012; AlvesSilva et al., 2020). Additionally, NPs could affect the viability or activity of microorganisms (cell wall/cell membrane/mitochondrial membranes) (Silva et al., 2019 Zuzarte et al., 2011). Secondly, NPs act through the modulation of host cells by activating or inhibiting the inflammation-associated signaling pathways of host cells infected by microorganisms, such as NF- $\mathrm{KB} / \mathrm{JNK} / \mathrm{MAPK} / \mathrm{p} 53$, to adjust the potential of enemy-destroying and self-destructive process to a better balance (Zhou et al., 2017; Han and Guo, 2012; Pang et al., 2011). Thirdly, NPs exert protective effects on cells through antioxidant mechanisms (Alam et al., 2012; Fankem et al., 2019; Reddy et al., 2010). Lastly, NPs can induce DNA damage (Singh et al., 2018), interfere with substance meta- bolism (Agarwal et al., 2008), exert immunomodulation (Basso et al., 2020) or autophagy modulation (Kaneda et al., 1991; Laconi et al., 2014).

Novel active skeleton compounds, such as Asperflavipine A, have become a topic of interest in NP research. Terpenoids, polyketones, alkaloids, and heterozygous KS-NRPS NPs have attracted considerable interest. Most of these NPs have anti-tumor, antibacterial, anti-inflammatory, and other biological activities. Novel NPs also have great potential because of their unique characteristics (Chen et al., 2020). The novel skeletons of heteroterpenes, such as Rhodomyrtusials derived from terpenoid biosynthesis, have shown great potential in studies of antibacterial activities. Due to their novel and diverse structural skeletons, they are widely distributed in microorganisms, including fungi and actinomycetes, sponges, Myrtaceae, Ericaceae, Lamiaceae, and some large fungi such as Ganoderma lucidum (Matsuda and Abe, 2016; Peng and Qiu, 2018; Zhao et al., 2020).

The hurdle remains in the researches of natural antimicrobial agent discoveries is that only the verification of their activity in vitro is effective, but insufficient research has been carried out in vivo, and the mechanisms of activity are difficult to explain, limiting the practical application of some effective NPs. The anti-microorganism mechanisms of NPs is the result of more than one mode of action, so the specific mechanism of an NP could be explored based on the integrated analysis of its effects on both the microorganism and the host cells, including studies of morphology, molecular mechanisms, and function. This is why the mechanisms of numerous conventional drugs have not been explored in depth. However, given the considerable potential of NPs for anti-microorganism activity, it is important to study their specific mechanisms of action (MOA).

\section{Compounds from natural sources which inhibit the five groups of pathogens}

In this section we provide a comprehensive analysis of the currently collected data using three approaches. To analyze the major classification of compounds selected and their chief MOAs, we used network pharmacology. To explore the structural relationships between NPs targeting different infectious pathogens, we calculated the maximum Tanimoto similarity scores between all molecule pairs of selected compounds. We also explored the diversity of their natural sources.

\section{Identification of different classes of natural product-based compounds based on network pharmacology}

From the collected data, we selected a total of 268 available NP-based compounds which have activity against 19 
infectious pathogens, including HBV, IAV, HSV, HIV, SARS-CoV, SARS-CoV-2, MERS-CoV, Salmonella typhi, Shigella, Mycobacterium tuberculosis, MRSA, Helicobacter pylori, Cryptococcus neoformans, Malassezia furfur, Plasmodium, Schistosoma, Trichomonas vaginalis, Leptospira, and prions. Information about the MOAs of the compounds against microorganisms was obtained from the literature, and a network diagram was constructed using Cytoscape 3.8.0 (Shannon et al., 2003) (Figure 2). Target genes of compounds with a minimum required interaction score (indicating the prediction of compound targets) greater than 0.7 (high confidence) were obtained from the STITCH website (Szklarczyk et al., 2016). Functional enrichment analysis of target genes and the graphical display of the results of the analysis were conducted using the ClueGO v2.5.7 plug-in of Cytoscape 3.8.0 software (Bindea et al., 2009) (Figure 3).

The 268 NP-based compounds were classified into ten categories: sugars and glycosides, quinonoids, penylpropanoids, flavonoids, terpenoids, steroids, alkaloids, tannins, polyphenols, fatty acids, amino acids, and sulfur compounds. Based on our analysis, the compounds the most credible evidence of activity were agelasine $\mathrm{D}$ and dicumarol against Mycobacterium tuberculosis; dihydroartemisinin against Plasmodium; and pyridomycin against Mycobacterium tuberculosis. Other promising interactions, which would repay further investigation, are compounds 1,8-cineole, borneol, camphene, berberine, and $\alpha$-pinene against Cryptococcus neoformans; artemisinin against Plasmodium; Baicalin, emodin, myricetin, and scutellarein against SARS-CoV; and methyl jasmonate against Trichomonas vaginalis (Figure 2).

The possible MOAs of four compounds baicalin, emodin, berberine, and quercetin against the above infectious pathogens were illustrated in detail, as they have shown the most abundant inhibition effects. The most plausible pathways are those related to immunoregulation, anti-inflammatory activities, and modification of the replication of DNA and translation of the proteins of infectious pathogens. For instance, emodin negatively regulates DNA metabolism and silencing by miRNA (Figure 3). Emodin can protect infected cells by inhibiting the replication and maturation of the EV71 virus (Zhong et al., 2017). This observation also suggests that emodin may play a role against pathogens such as HIV and HSV by inhibiting their DNA replication.

These four compounds regulate similar signaling pathways, including (i) inflammation-immune-response-related signaling pathways: after pathogenic microorganisms infect body cells, they induce a series of inflammatory and immune responses to resist the invasion of pathogenic microorganisms (Häcker, 2018), which helps to regulate the response to infection. For example, emodin can regulate the production of chemokines and TNF- $\alpha$; berberine can regulate IL- $1 \beta$; and quercetin can regulate the production of IL- 8 and chemokines. (ii) Apoptosis-related signaling pathways, infec- tion, and the subsequent excessive inflammation and immune response may induce apoptosis and cell damages (Zhang and Wang, 2014). These four compounds can regulate apoptosis-related signaling pathways, and may reverse cell damage through this common mechanism.

\section{Chemical diversity of available natural product-based compounds}

To explore the structural relationships of NPs targeting different infectious pathogens, we calculated the maximum Tanimoto similarity scores between all molecule pairs of the selected compounds. A total of 268 NP-based compounds targeting 19 pathogenic organisms from five categories were collected: virus (HBV, IAV, HSV, HIV, SARS-CoV, SARSCoV-2, and MERS-CoV); bacteria (Salmonella typhi, Shigella, Mycobacterium tuberculosis, MRSA, and Helicobacter pylori); fungus (Cryptococcus neoformans, and Malassezia furfur); parasites (Plasmodium, Schistosoma, and Trichomonas vaginalis) and others (Leptospira and prions). The molfiles of the compounds in the Canonical SMILES format were downloaded from the ChEMBL online database (Gaulton et al., 2016). The Tanimoto similarity was calculated using a Perl program rewritten based on MolPrint 2D (Kong et al., 2011). To examine the relationship between the targeted pathogen types and the chemical diversity we subdivided the dataset into five subgroups (virus, bacterium, fungus, parasite, and others) (Pye et al., 2017).

Figure 4 shows that compounds, especially those inhibiting parasites, had high similarity, with a relatively large "hammerhead" distribution. Compared with the other subgroups, particularly the bacteria, fungi, and viruses, the distribution of the maximum Tanimoto scores is centered at relatively low values, suggesting that the chemistries of the compounds inhibiting these pathogenic organisms show high structural diversity. The targets and mechanisms of inhibition of parasites might be relatively less diversified comparing with those against bacteria and viruses, which contain a variety of targets and use different approaches. However, except for the "others" subgroup, the maximum Tanimoto scores of all infectious pathogens are considered to be high $(\mathrm{T}>0.4)$. These results indicate that, in the absence of significant innovation in discovery approaches, there are diminishing returns in terms of the discovery of fundamentally new chemical diversity from continued investigations into the same classes of natural sources. These conclusions agree with those of Pye et al. (2017). Therefore, more efforts should be paid to exploring novel targets, deciphering mechanisms, and discovering compounds. Recently, there have been some efforts to describe NP chemical space and to use this space as a boundary for designing NP-like synthetic screening libraries (Rosén et al., 2009; Pascolutti et al., 2015). For a given biosynthetic class of NPs, a huge number 


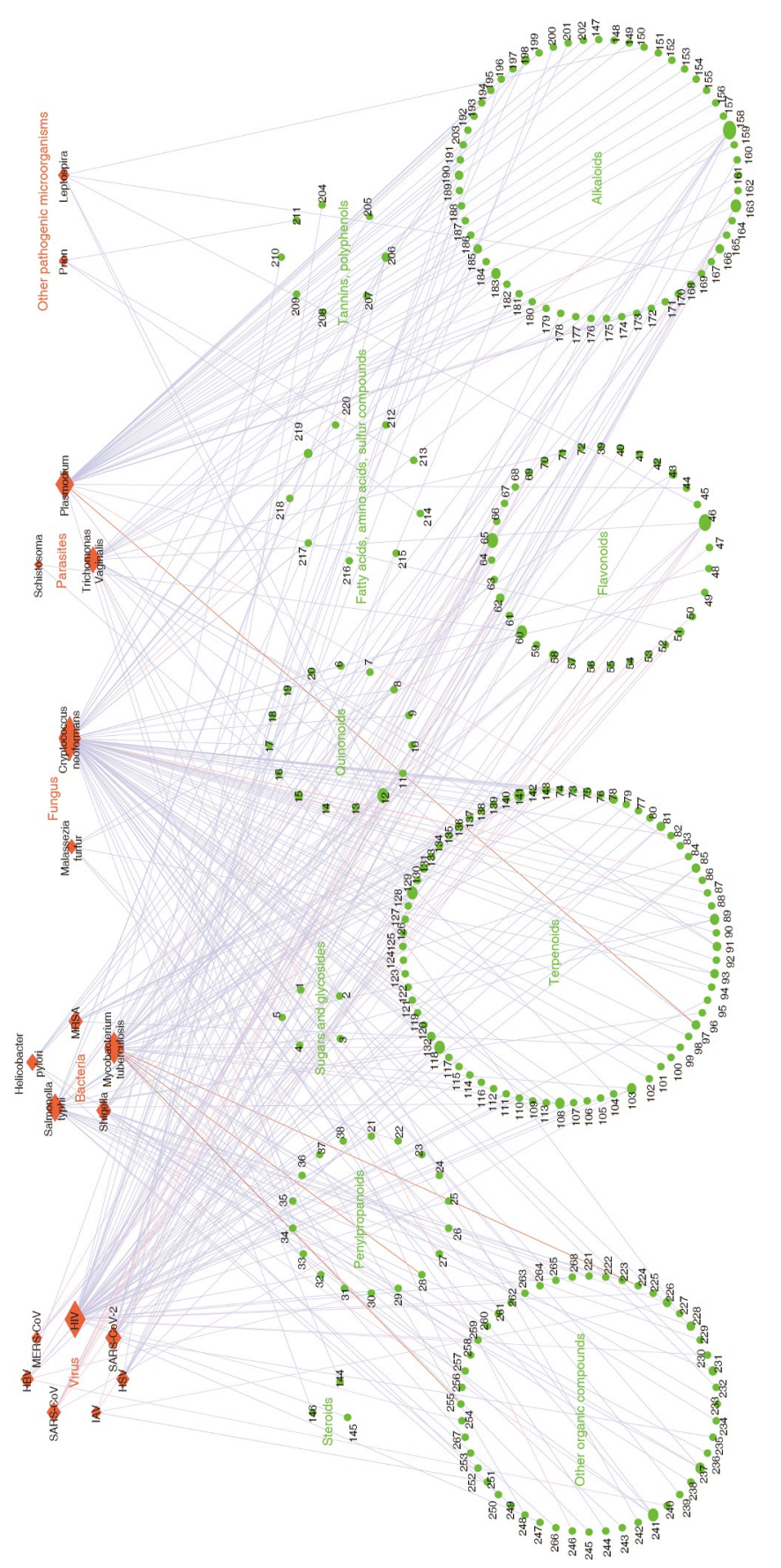

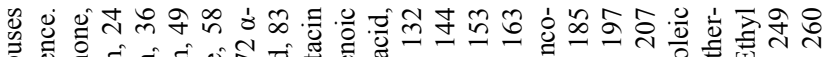

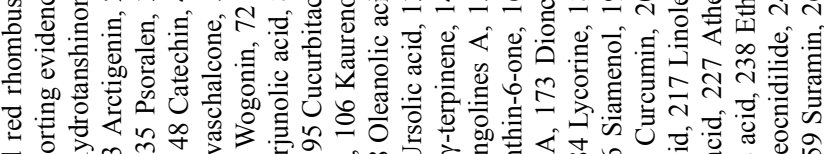

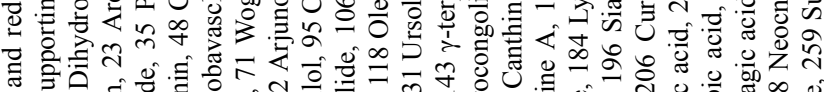

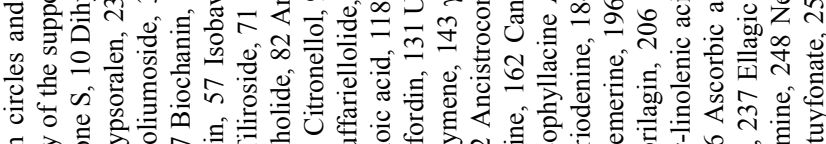

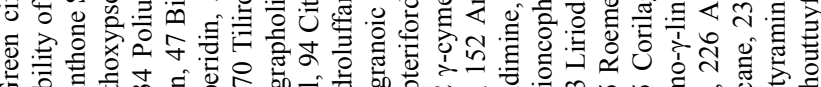

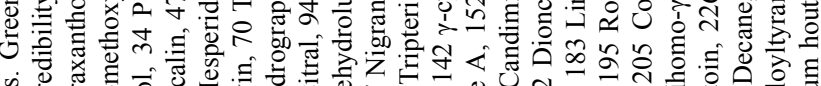

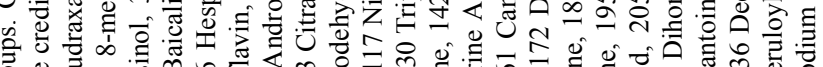

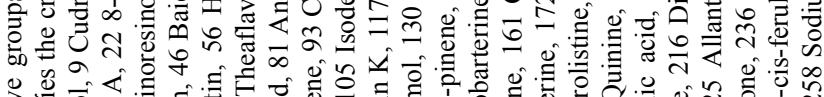

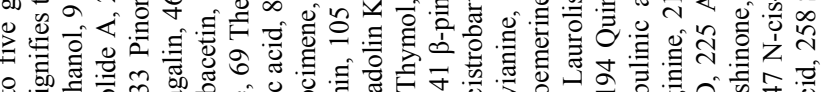

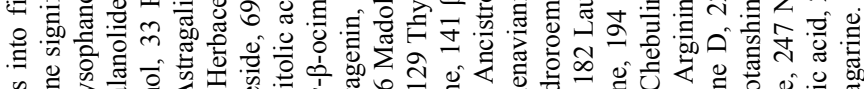

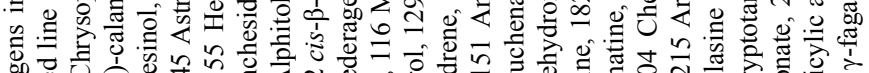

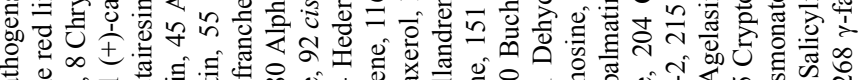

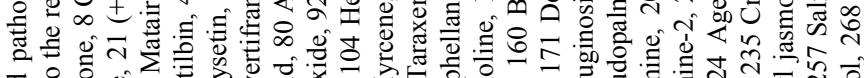

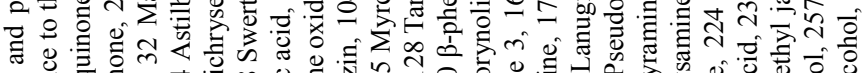

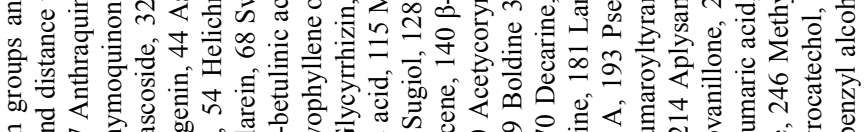

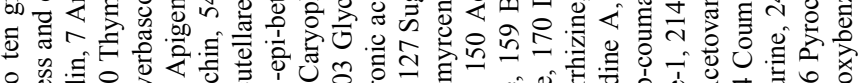

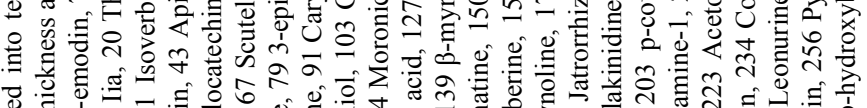

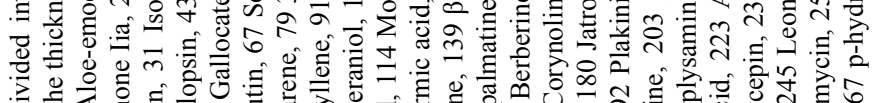

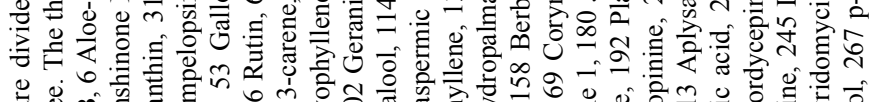

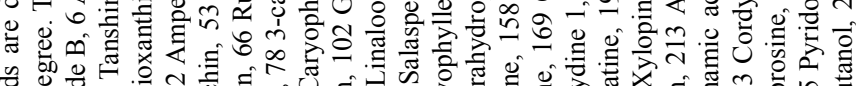

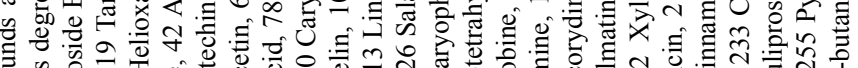

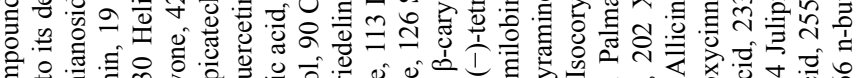

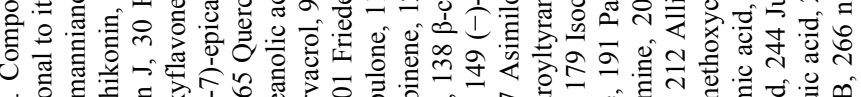

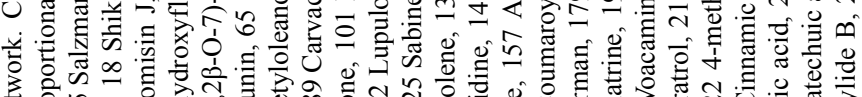

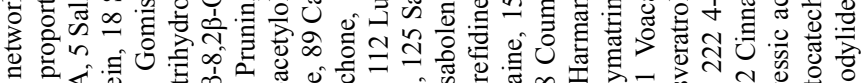

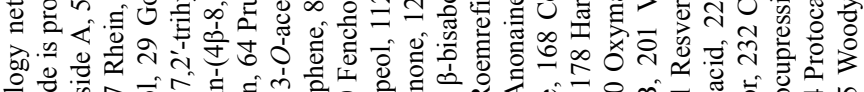

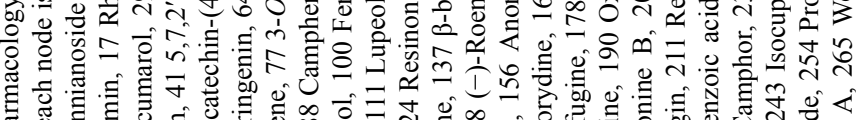

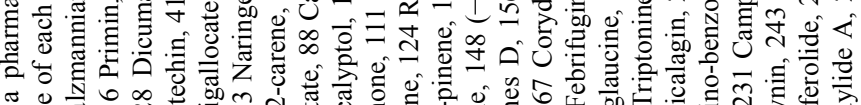

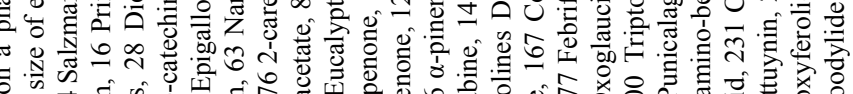

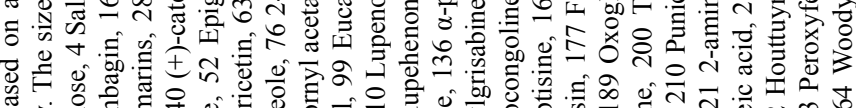

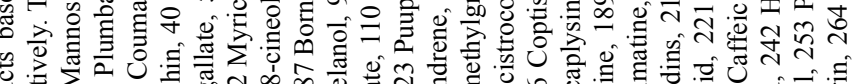

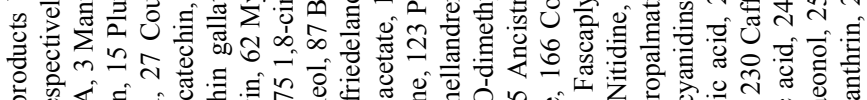

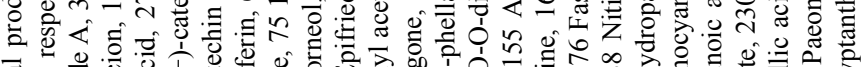

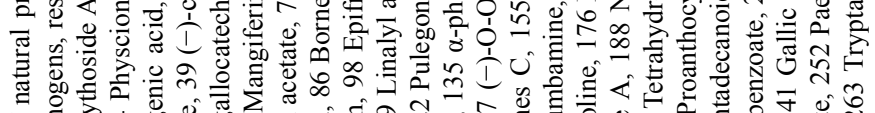

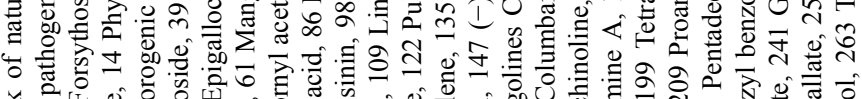

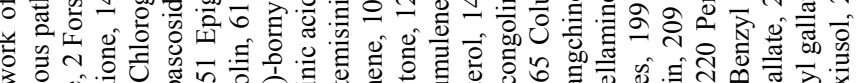

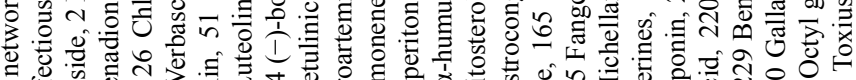

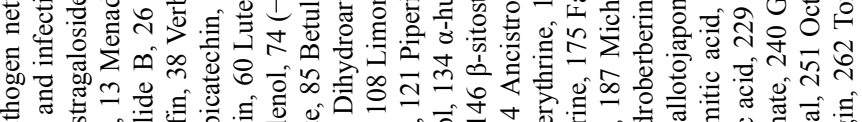

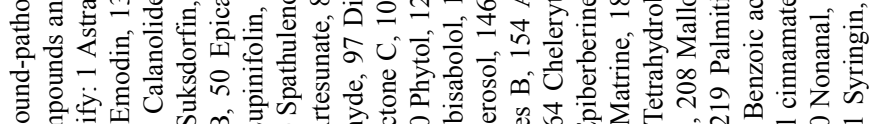

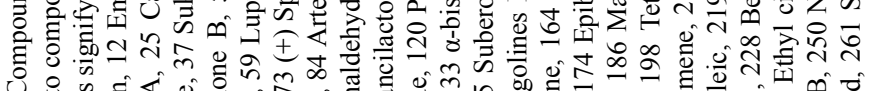

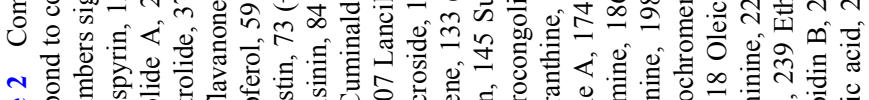

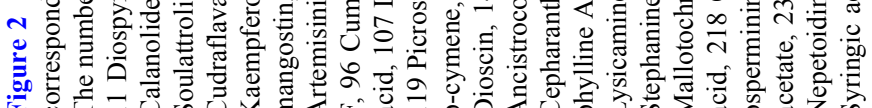




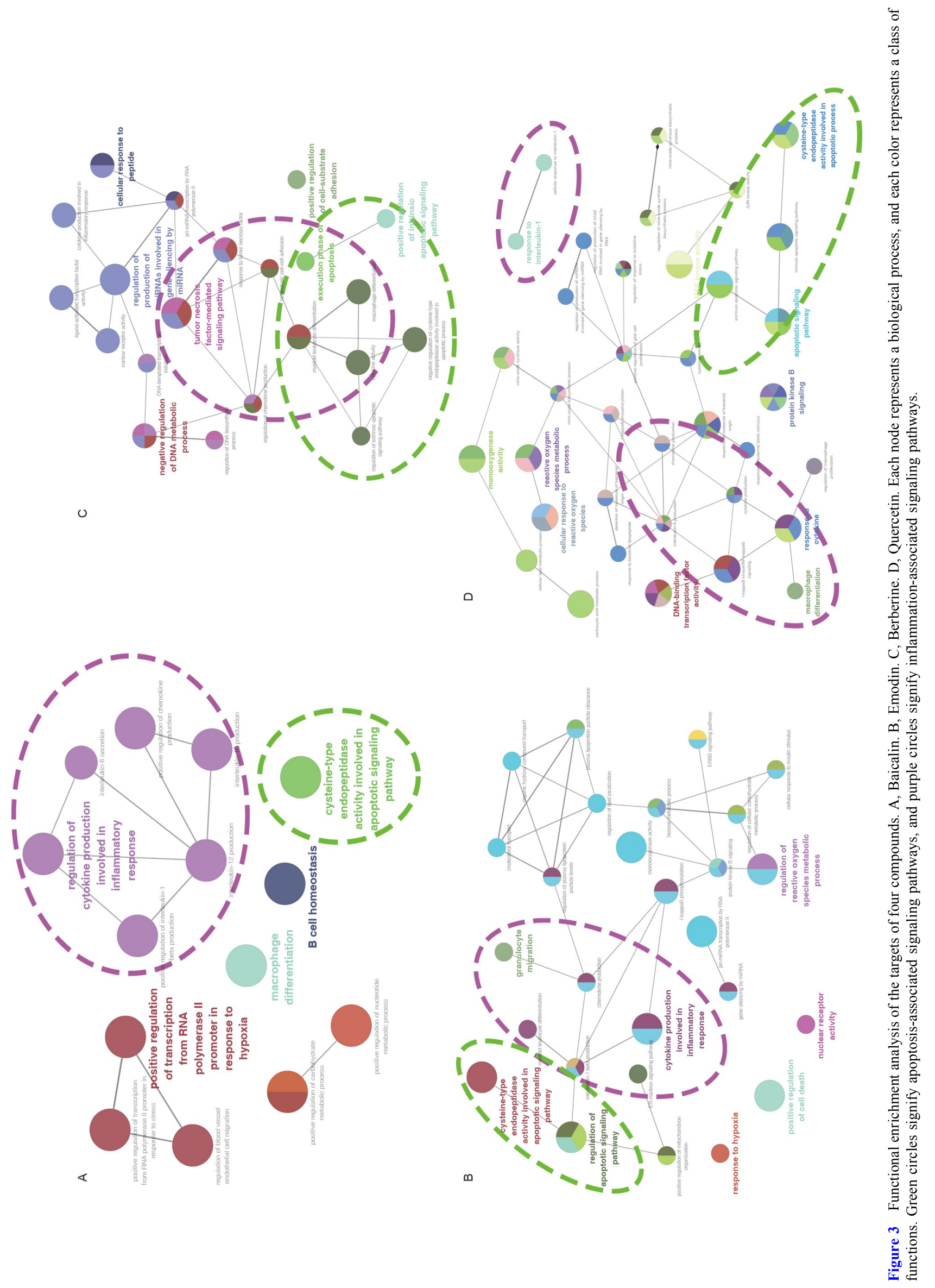




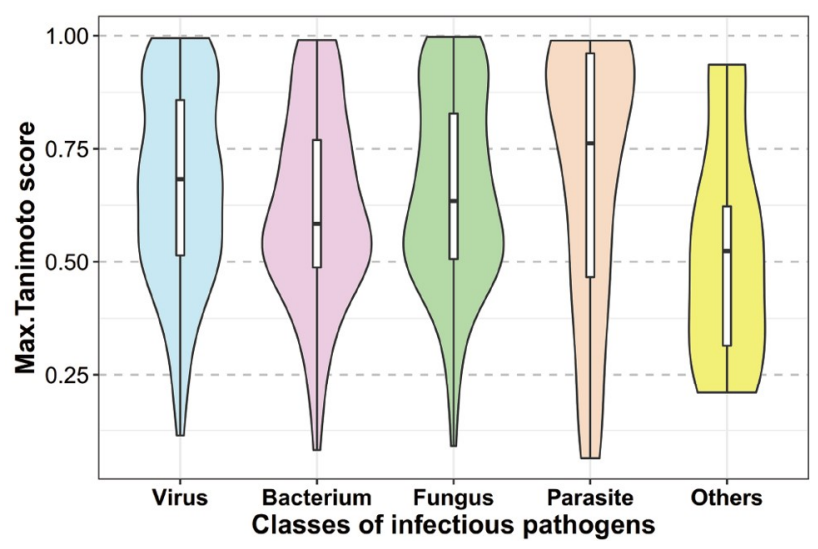

Figure 4 Violin plots of maximum Tanimoto scores of compounds among five categories of infectious pathogens.

of theoretical molecules can be created from primary building blocks such as amino acids, sugars, acetate, and propionate. Using these diverse and often chiral components, NP libraries should, therefore, exceed synthetic libraries in terms of the structural diversity of chemical scaffolds (Pye et al., 2017).

\section{Classification of families of medicinal plants known to produce compounds inhibiting pathogenic microorgan- isms}

Using the most reliable data, we collected information about compounds targeting four pathogenic organisms from four subgroups: C. neoformans (fungus), Salmonella typhi (bacterium), HIV (virus), and Plasmodium (parasite), to explore the diversity of their natural sources. A subset of 331 species of medicinal plants known to produce compounds with biological activities against the above four pathogenic microorganisms was collected from the literature. Data about 129 species producing NPs were collected for C. neoformans, 62 species for HIV, 26 for Plasmodium, and 114 for Salmonella typhi. In order to visualize the lineages selected above, four species trees with the different subgroup of compounds based on the chloroplast genome (Figure 5) were constructed in R 3.4.2 (The R Core Team, 2013) with the "phytools" package, using the function S.PhyloMaker (Qian and Jin, 2016). The backbone of the tree and nodes was obtained together with the S.PhyloMaker script (Qian and Jin, 2016). The tree was visualized and annotated in iTOL (Letunic and Bork, 2016).

NP-based compounds were relatively more abundant in the Asteraceae, Celastraceae, Lamiaceae, and Myrtaceae families for C. neoformans; the Anacardiaceae, Asteraceae, Euphorbiaceae, Lamiaceae, Leguminosae, and Polygonaceae families for Salmonella typhi; the Cucurbitaceae, Euphorbiaceae, Lamiaceae, Rutaceae, and Schisandraceae families for HIV; and the Ancistrocladaceae, Annonaceae,
Apocynaceae, Lauraceae, and Zingiberaceae families for Plasmodium (Figure 5). We concluded that, though the discovery of unexplored and unusual sources provides opportunities for finding novel NPs, NP-based compounds from the same family, genera or species may share similar secondary metabolic pathways, mechanisms, and targets, in which specific synthetic pathways could be further explored.

Based on the above analysis, sugars and glycosides, quinonoids, penylpropanoids, flavonoids, terpenoids, steroids, alkaloids, tannins, polyphenols, fatty acids, amino acids, and sulfur compounds from NP sources are the ten most promising compounds against infectious pathogens (Table 1). Inflammation and immune response-related signaling pathways and apoptosis-related signaling pathways are the two major pathways through which these compounds act against pathogenic microorganisms. The NP library is in need of further exploration, especially for the identification of novel targets and the deciphering of mechanisms, as the structural diversity of chemical scaffolds is of great abundance. The families Asteraceae, Celastraceae, Anacardiaceae, Cucurbitaceae, Ancistrocladaceae and associated genera and species are found to contain abundant compounds which act against specific pathogenic microorganisms. Synthetic versions of these pathways should be further explored, to discover effective compounds. The targets and mechanisms for inhibiting bacteria and viruses are diverse. More efforts should be put into exploring novel targets, deciphering mechanisms of action, and discovering compounds in NP-like synthetic screening libraries.

\section{In silico methods for the identification of natural product-based compounds}

NP drug discovery is a multidimensional problem, requiring the consideration of several factors for both natural and synthetic compounds, including safety, pharmacokinetics, and efficacy, to be evaluated during the selection of drug candidates (Chi et al., 2006). NP discovery is achieved using two main approaches. As the conventional "top-down" approach has already been largely abandoned (Jensen et al., 2014), the advent of latest technologies such as artificial intelligence (AI), "organ-on-chip", and microfluidics technologies (Chi et al., 2006) has bolstered the emergent "bottom-up" approach, offering the capacity to access the unexpressed genetic potential of microorganisms (Bachmann et al., 2014). Recent advances in analytical and computational techniques have made possible new approaches to the analysis of complex NPs, to design synthetic versions of compounds and to derive new and innovative drugs (Chi et al., 2006). Metabolic pathway engineering and synthetic biology have transformed NP discovery, production, and engineering (Pye et al., 2017). 

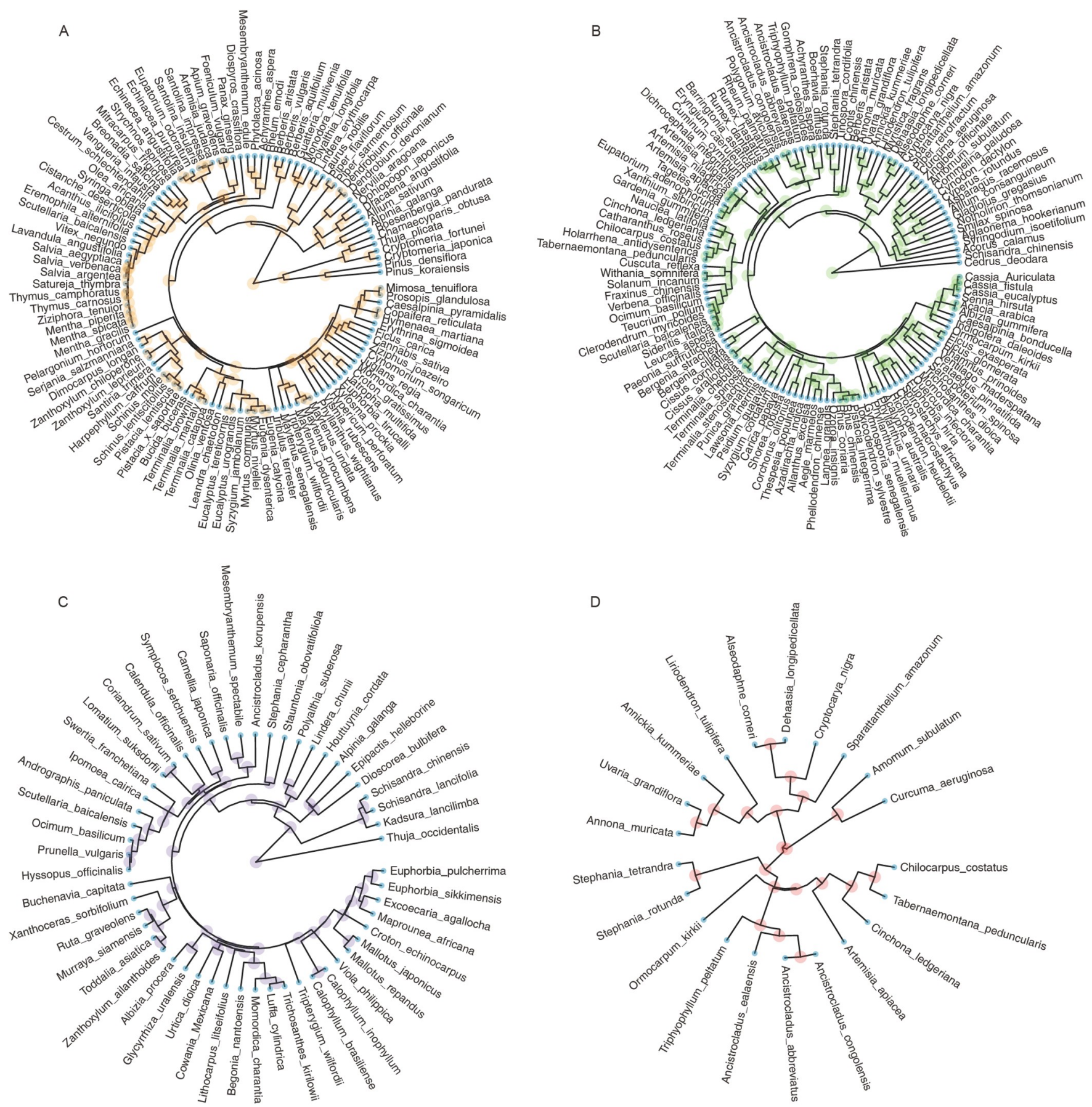

Figure 5 Four species trees of medicinal plants for the known compounds in (A) Crytococcus neoformans, (B) Salmonella typhi, (C) HIV, and (D) Plasmodium, based on the chloroplast genome.

The area of NP discovery in silico is becoming increasingly active, mainly due to the reduced time, risks, and resources taken by this approach compared to traditional experimental approaches (Luo et al., 2020) (Figure 6). Computational models can be used to identify inadequate knowledge about the targets of NP, undesirable pharmacokinetic expressions upon target interaction, or off-target effects. Therefore, it is necessary to implement in silico methods and powerful data resources to facilitate the design and redesign of NP-like molecules with desired bioactivity, and to predict and validate NP targets. There is an urgent need to find therapeutic NPs when infectious diseases are prevalent (Trosset and Cavé, 2019). NPs have a large quantity of lead-like molecules, which could be used as scaffolds to expand the chemical library (Gu et al., 2013). Chemical similarity search depends heavily on the existence of reference compounds for known targets, and the availability of data about existing NPs or preclinical NP 
Table 1 Species of natural products with most abundant compounds against infectious pathogens, taken from the literature

\begin{tabular}{|c|c|c|c|}
\hline No. & $\begin{array}{l}\text { Species of natural } \\
\text { products }\end{array}$ & Representative compounds & Infectious pathogens \\
\hline 1 & Sideritis italica & $\begin{array}{c}\beta \text {-Pinene, } \beta \text {-Cubebene, } \beta \text {-Bisabolene, } \alpha \text {-Bisabol, tricyclene, p-Metoxyacetophenone, } \\
\text { palmitic acid, m-Metoxyacetophenone, limonene, carvacrol, camphor, benzyl } \\
\text { benzoate, } \Delta 3 \text {-Carene, nuciferol, nonanal, and kaur-15-ene }\end{array}$ & Salmonella typhi \\
\hline 2 & Barringtonia asiatica & $\begin{array}{l}\text { Uncineol, tetradecanol, humulene oxide, hexyl hexanoate, geranyl butyrate, ethyl } \\
\text { valerate, ethyl lactate, eicosane, decane, acetovanillone, 4-Propyl-guaiacol, and (Z)-4- } \\
\text { decenal, (-)-c-elemene }\end{array}$ & Salmonella typhi \\
\hline 3 & Juglans regia & $\begin{array}{l}\text { Quercetin 3-xyloside, quercetin 3-rhamnoside, quercetin 3-galactoside, quercetin 3- } \\
\text { arabinoside, p-coumaric acid, palmitic acids, linoleic acid, 4-p-coumaroylquinic acids, } \\
\text { 3-caffeoylquinic acids, 5-caffeoylquinic acids, 3-p-coumaroylquinic acids, and oleic }\end{array}$ & MRSA, Cryptococcus neoformans \\
\hline 4 & Cannabis sativa & $\begin{array}{l}\beta \text {-sitosterol, pentadecanoic acid, p-coumaroyltyramine, methyl hexadecanoate, } \\
\text { friedelan-3-one, ergost-5-en-3-ol, epifriedelanol, 4-hydroxy-3-methoxybenzaldehyde, } \\
\text { 10E-hexadecenoic acid, naringenin, and } \beta \text {-sitosterol- } \beta \text {-D-glucoside }\end{array}$ & $\begin{array}{c}\text { MRSA, Cryptococcus neoformans, } \\
\text { Helicobacter pylori }\end{array}$ \\
\hline 5 & $\begin{array}{l}\text { Ancistrocladus } \\
\text { abbreviatus }\end{array}$ & $\begin{array}{l}\text { Ancistrobrevine J, ancistrobrevine I, ancistrobrevine } \mathrm{H} \text {, ancistrobrevine } \mathrm{G} \text {, ancistro- } \\
\text { brevine F, ancistrobrevine E, 6-O-Demethylancistrobrevine H, 5-epi-Ancistrobrevine } \\
\text { F, 5-epi-Ancistrobrevine E, and 5'-O-Demethylancistrobrevine B }\end{array}$ & Plasmodium \\
\hline 6 & Piper flaviflorum & $\begin{array}{l}\text { Sarmentine, piperyline, piperolactam D, pellitorine, homopellitorine, demethoxypi- } \\
\text { plartine, brachyamide B, } 1-[(2 \mathrm{E}, 4 \mathrm{E}, 9 \mathrm{E})-10-(3,4-\text { methylenedioxyphenyl)-2,4,9-unde- } \\
\text { catrienoyl]pyrrolidine, (2E,6E)-sarmentosine, and (2E)-decenoylpiperidide }\end{array}$ & Cryptococcus neoformans \\
\hline 7 & Ecdysanthera rosea & $\begin{array}{l}\text { Pregnane glycoside ecdysantheroside A, C-21 pregnane glycoside ecdysosides H, } \\
\text { C-21 pregnane glycoside ecdysosides G, C- } 21 \text { pregnane glycoside ecdysosides F, } \\
\text { C-21 pregnane glycoside ecdysosides E, C-21 pregnane glycoside ecdysosides D, } \\
\text { C-21 pregnane glycoside ecdysosides C, C- } 21 \text { pregnane glycoside ecdysosides B, } \\
\text { and C- } 21 \text { pregnane glycoside ecdysosides A }\end{array}$ & Cryptococcus neoformans \\
\hline 8 & Guatteria multivenia & $\begin{array}{c}\text { Dihydromadolin-K, guadiscine, guatterin A, lanuginosine, liriodenine, lysicamine, } \\
\text { madolin-K, madolin-W, and o-methylpallidine }\end{array}$ & MRSA, Cryptococcus neoformans \\
\hline 9 & Pinus koraiensis & $\begin{array}{l}\text { Limonene, isolongifolene, caryophyllene, camphene, } \beta \text {-pinene, } \beta \text {-myrcene, alpha- } \\
\text { pinene, and 3-carene, }(-) \text {-bornyl acetate }\end{array}$ & Cryptococcus neoformans \\
\hline 10 & Stephania rotunda & $\begin{array}{c}\text { Xylopinine, vireakine, tetrahydropalmatine, stephanine, roemerine, pseudopalmatine, } \\
\text { palmatine, dehydroroemerine, and cepharanthine }\end{array}$ & Plasmodium \\
\hline 11 & Liriodendron tulipifera & $\begin{array}{c}\text { Peroxyferolide, oxoglaucine, norushinsunine, norglaucine, liriodenine, lipiferolide, } \\
\text { asimilobine, and anonaine }\end{array}$ & Plasmodium \\
\hline 12 & $\begin{array}{l}\text { Tripterygium } \\
\text { wilfordii }\end{array}$ & $\begin{array}{l}\text { Triptonine B, tripteryols } \mathrm{C} \text {, tripteryols } \mathrm{B} \text {, tripteryols A, tripterifordin, salaspermic } \\
\left.\text { acid, }( \pm)-5,4^{\prime}-\text { dihydroxy-2'-methoxy-6', 6"-dimethypyraro-( } 2^{\prime \prime}, 3^{\prime \prime}: 7,8\right)-6 \text {-methyflava- } \\
\text { none, (2S)-5,7,4'-trihydroxy-2'-methoxy-8, and 5'-di(3-methyl-2-butenyl)-6-methyl- } \\
\text { flavanone }\end{array}$ & HIV, Cryptococcus neoformans \\
\hline
\end{tabular}

candidates (Mujawar et al., 2018). We collected databases from the literature (Table 2). Virtual NP databases can be categorized into (i) encyclopedic and general NP databases, (ii) databases enriched with NPs used in traditional medicines, and (iii) specialized databases focused on specific habitats, geographical regions, organisms, biological activities, or even specific NP classes. However, the availability of materials for experimental evaluation produces a bottleneck in NP-based drug discovery, as many of those resources do not offer free downloads (Kinghorn et al., 2019).

In silico methods have strongly impacted the way in which new targets are identified for old ligands (Keiser et al., 2009; Cameron et al., 2013), the prediction of side effects (Lounkine et al., 2012), and the development of anatomical therapeutic indicators of approved ligands (Wu et al., 2013). Over the past few decades, several strategies have become important, including network-based analysis; molecular docking; ligand-based and structure-based approaches, including chemical structures and reactions; protein structure; protein-protein interactions; signal transduction; genetic interactions; and metabolic networks (Agamah et al., 2020).
These strategies have been widely used to predict candidate targets and ligand-target interactions. Molecular docking is used to predict the geometry and score the interactions of proteins in complex with small-molecule ligands (Kitchen et al., 2004). These methods can be used to predict whether a given ligand is potentially able to bind other targets. Ligandbased analysis indicates that similar compounds tend to have similar biological properties, and have been extensively used to analyze and predict the activity of ligands for new targets (March-Vila et al., 2017). Structure-based analysis is based upon the idea that proteins with similar structures are likely to have the same functions, and to recognize related ligands. In the field of drug repurposing, protein comparison is used as a method to identify secondary targets of an approved ligand (Ehrt et al., 2016) (Figure 6A and B).

Machine learning (ML) or data mining (DM) approaches have permeated in silico methods, and play critical roles in uncovering significant patterns in chemical and pharmacological property space, which are essential for compound discovery. Advanced machine learning models and algorithms such as support vector machines (Burbidge et al., 

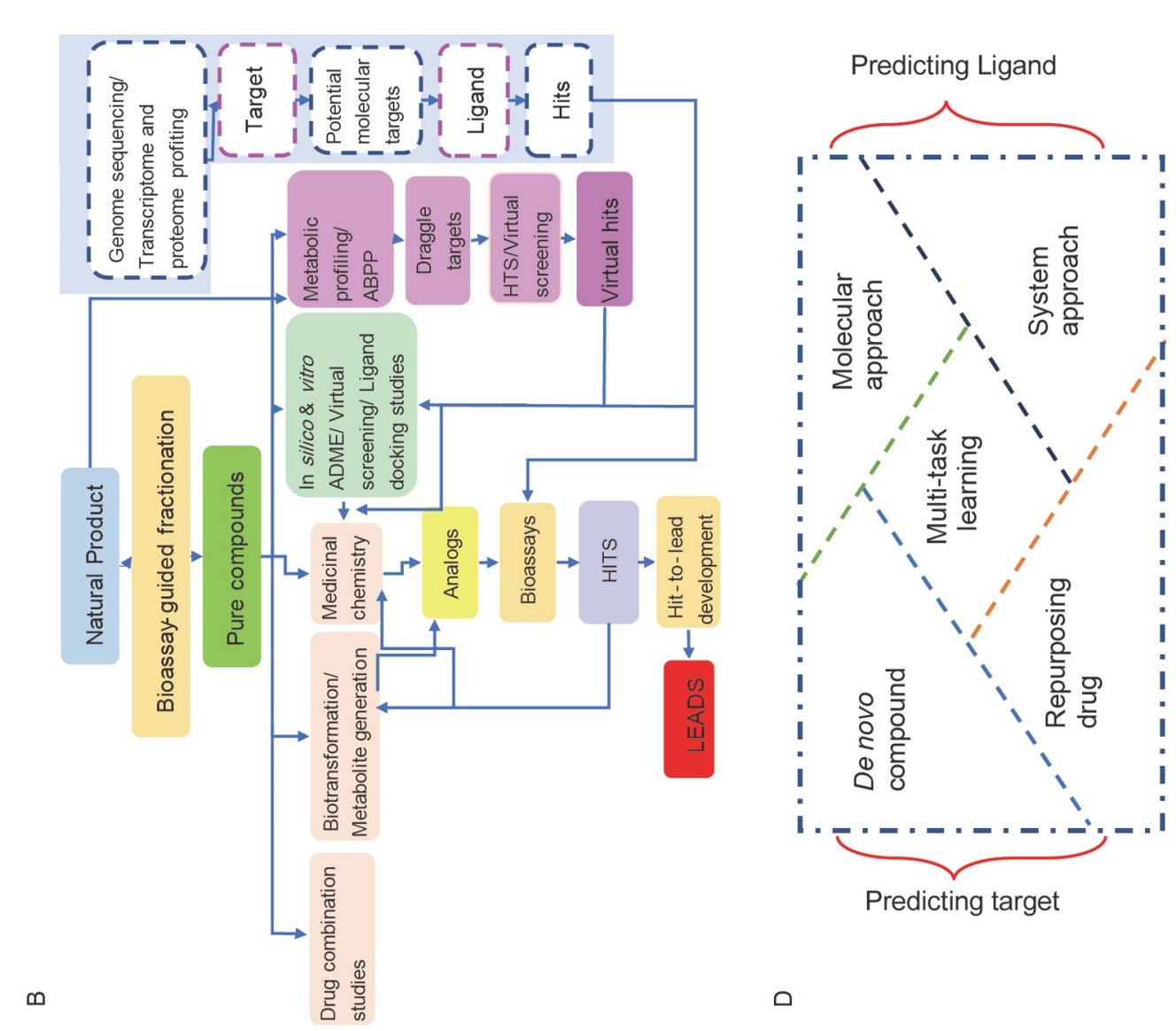

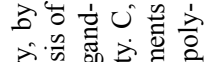

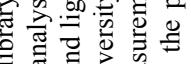

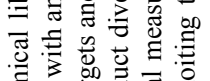

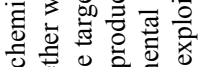

0

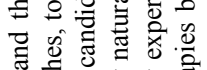

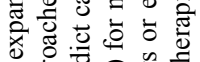

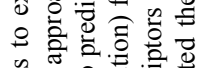

웡 元

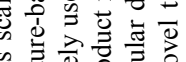

记

的可

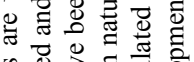

记

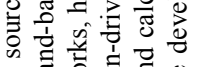

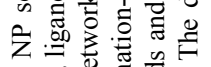

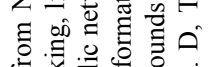

\& $\begin{aligned} & 0.0 \\ & 0\end{aligned}$

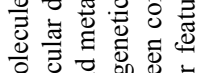

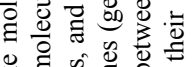

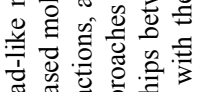

๘

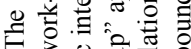

\&

is

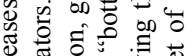

.

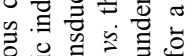

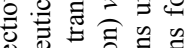

岂

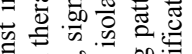

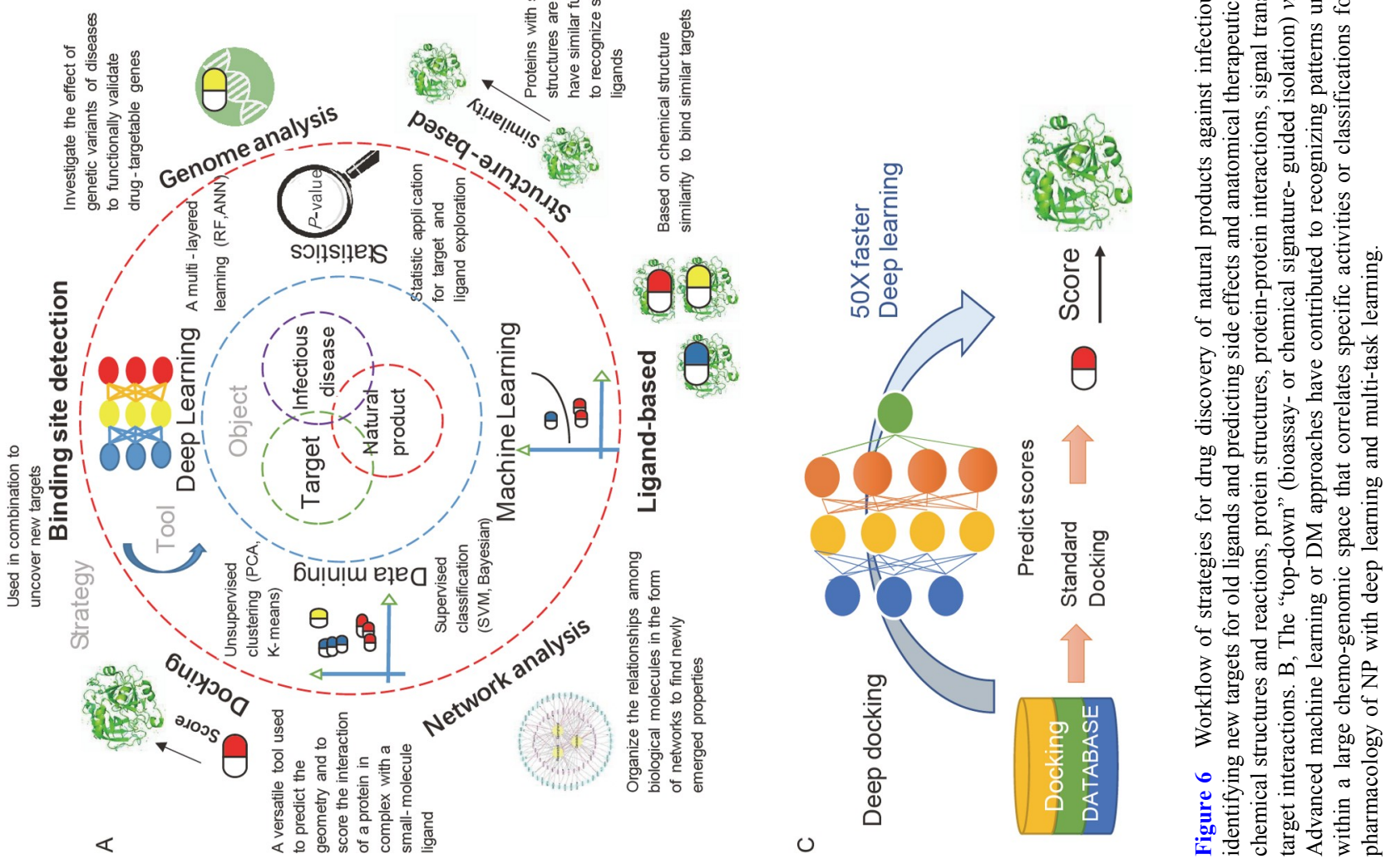


Table 2 Databases available for in silico analysis of natural products

\begin{tabular}{|c|c|c|c|}
\hline Database & Description & URL & Reference \\
\hline Binding database (BindingDB) & Protein binding database & https://www.bindingdb.org & Kirchmair et al., 2015 \\
\hline ChEMBL & Drug bioactivity data & $\begin{array}{l}\text { https://www.ebi.ac.uk/ } \\
\text { chembl/ }\end{array}$ & Bento et al., 2014 \\
\hline Chinese Natural Product Database (CNPD) & Chinese Natural Product Database & $\begin{array}{l}\text { https://www.neotrident. } \\
\text { com/ }\end{array}$ & Shen et al., 2003 \\
\hline $\begin{array}{l}\text { Comparative Toxicogenomics Database } \\
\text { (CTD) }\end{array}$ & Gene-Drug-Disease interactions & http://ctdbase.org/ & Davis et al., 2017 \\
\hline $\begin{array}{l}\text { The Drug Gene Interaction Database } \\
\text { (DGIdb) }\end{array}$ & Gene-Drug interactions & $\begin{array}{l}\text { http://dgidb.genome.wustl. } \\
\text { edu }\end{array}$ & Wagner et al., 2016 \\
\hline Drug Repurposing & Drug repurposing & https://clue.io/repurposing & Corsello et al., 2017 \\
\hline DrugBank & Gene-Drug interactions and drug information & https://www.drugbank.ca/ & Law et al., 2014 \\
\hline Hetionet & $\begin{array}{l}\text { Combination of } 29 \text { public databases on genes, } \\
\text { diseases, drugs, and side effects }\end{array}$ & https:/het.io/ & Himmelstein et al., 2017 \\
\hline Illuminating the Druggable Genome & Drug-targeted protein families & $\begin{array}{l}\text { https://druggablegenome. } \\
\text { net/ }\end{array}$ & Rodgers et al., 2018 \\
\hline $\begin{array}{l}\text { Kyoto Encyclopedia of Genes and Gen- } \\
\text { omes (KEGG) }\end{array}$ & Drug Information on drugs and targets & $\begin{array}{l}\text { https://www.genome.jp/ } \\
\text { kegg/drug/ }\end{array}$ & Kanehisa and Goto, 2000 \\
\hline $\begin{array}{l}\text { Library of Integrated Network-Based Cel- } \\
\text { lular Signatures (LINCS) }\end{array}$ & Gene expression and drugs & $\begin{array}{l}\text { http://www.lincsproject. } \\
\text { org/ }\end{array}$ & Keenan et al., 2018 \\
\hline NCGC Pharmaceutical Collection (NPC) & $\begin{array}{l}\text { A comprehensive, publically-accessible collection of } \\
\text { approved and investigational drugs for high-through- } \\
\text { put screening that provides a valuable resource for } \\
\text { both validating new models of disease and better } \\
\text { understanding the molecular basis of disease pathol- } \\
\text { ogy and intervention }\end{array}$ & https://tripod.nih.gov/npc/ & Huang et al., 2011 \\
\hline Orphanet & Rare diseases and orphan drugs & http://www.orpha.net & Pavan et al., 2017 \\
\hline Pharos & Knowledgebase for the druggable genome & $\begin{array}{l}\text { https://pharos.nih.gov/idg/ } \\
\text { index }\end{array}$ & Nguyen et al., 2017 \\
\hline PubChem & Chemical database & $\begin{array}{l}\text { https://pubchem.ncbi.nlm. } \\
\text { nih.gov/ }\end{array}$ & Kim et al., 2016 \\
\hline repoDB & Clinical trial and repositioning database & $\begin{array}{l}\text { http://apps.chiragjpgroup. } \\
\text { org/repoDB/ }\end{array}$ & Brown and Patel, 2017 \\
\hline Side Effect Resource & $\begin{array}{l}\text { information on marketed medicines and their } \\
\text { recorded adverse drug reactions }\end{array}$ & http://sideeffects.embl.de/ & Kuhn et al., 2016 \\
\hline STITCH & Chemical-protein interaction networks & http://stitch.embl.de/ & Szklarczyk et al., 2016 \\
\hline SuperTarget & Drug targets and side effects & $\begin{array}{l}\text { http://insilico.charite.de/ } \\
\text { supertarget/ }\end{array}$ & Hecker et al., 2012 \\
\hline $\begin{array}{l}\text { The Toxin and Toxin Target Database } \\
\text { (T3DB) }\end{array}$ & Gene-toxin database & http://www.t3db.ca/ & Wishart et al., 2015 \\
\hline TCM Database & Drug screenings of Traditional Chinese medicine & http://tcm.cmu.edu.tw/ & Chen, 2011 \\
\hline $\begin{array}{l}\text { Traditional Chinese Medicine database } \\
\text { (TCMDb) }\end{array}$ & $\begin{array}{l}\text { Chinese herbal medicines, components, } \\
\text { targets, and diseases }\end{array}$ & http://166.111.57.233/ & He et al., 2001 \\
\hline \multicolumn{2}{|c|}{ Traditional Chinese Medicine integrated database (TCMID) } & $\begin{array}{l}\text { http://www.megabionet. } \\
\text { org/tcmid/ }\end{array}$ & Xue et al., 2013 \\
\hline \multicolumn{2}{|c|}{ Traditional Chinese Medicine Systems Pharmacology (TCMSP) } & $\begin{array}{l}\text { http://www.tcmspw.com/ } \\
\text { tcmsp.php }\end{array}$ & Ru et al., 2014 \\
\hline Transformer & Cytochrome-drug interactions & $\begin{array}{l}\text { http://bioinformatics.char- } \\
\text { ite.de/transformer/ }\end{array}$ & Hoffmann et al., 2014 \\
\hline Therapeutic Target Database & Drug targets & $\begin{array}{l}\text { http://bidd.nus.edu.sg/ } \\
\text { group/cjttd/ }\end{array}$ & Chen et al., 2002 \\
\hline UniProt & Protein database & www.uniprot.org/ & Consortium, 2015 \\
\hline $\begin{array}{l}\text { Universal Natural Product Database } \\
\text { (UNPD) }\end{array}$ & $\begin{array}{c}\text { a comprehensive resource of natural products for } \\
\text { virtual screening }\end{array}$ & $\begin{array}{l}\text { http://pkuxxj.pku.edu.cn/ } \\
\text { UNPD }\end{array}$ & Gu et al., 2013 \\
\hline YaTCM & $\begin{array}{l}\text { Linking traditional Chinese medicine to targets and } \\
\text { diseases }\end{array}$ & $\begin{array}{l}\text { http://cadd.pharmacy.nan- } \\
\text { kai.Edu.cn/yatcm/home }\end{array}$ & Li et al., 2018 \\
\hline Super Natural & bio/cheminformatics and personalized medicine & $\begin{array}{l}\text { http://bioinformatics.char- } \\
\text { ite.de/supernatural/ }\end{array}$ & Hoffmann et al., 2014 \\
\hline
\end{tabular}




\begin{tabular}{|c|c|c|c|}
\hline Database & Description & URL & Reference \\
\hline Super Natural II & $\begin{array}{l}\text { 2D structures; vendor information for over } 215,000 \\
\text { compounds }\end{array}$ & $\begin{array}{l}\text { http://bioinf-applied.char- } \\
\text { ite.de/supernatural_new/in- } \\
\text { dex.php }\end{array}$ & Tsai et al., 2011 \\
\hline Universal Natural Product Database & $\begin{array}{l}\text { 3D structures assembled from other available Chinese } \\
\text { databases }\end{array}$ & $\begin{array}{l}\text { http://pkuxxj.pku.edu.cn/ } \\
\text { UNPD/introduction.php }\end{array}$ & Gu et al., 2013 \\
\hline Drug Discovery Portal & $\begin{array}{l}\text { A collection of biological target and computational } \\
\text { tests for potential drug candidates using the physics of } \\
\text { molecular interactions }\end{array}$ & $\begin{array}{l}\text { https://drugdiscovery.tacc. } \\
\text { utexas.edu/\#/ }\end{array}$ & Clark et al., 2010 \\
\hline $\begin{array}{l}\text { Medicinal plant Activities, Phytochemicals } \\
\text { \& structural database }\end{array}$ & $\begin{array}{l}\text { Medicinal plant activities, phytochemical and } \\
\text { structural database }\end{array}$ & $\begin{array}{l}\text { http://www.mapsdatabase. } \\
\text { com }\end{array}$ & Schuster et al., 2010 \\
\hline AfroDb & Compounds from African medicinal plants & $\begin{array}{l}\text { https://omictools.com/ } \\
\text { afrodb-tool }\end{array}$ & Ntie-Kang et al., 2013 \\
\hline $\begin{array}{l}\text { Universal Natural Products Database } \\
\text { (UNPD) }\end{array}$ & $\begin{array}{l}\text { A largest non-commercial and freely available } \\
\text { database for natural products }\end{array}$ & $\begin{array}{l}\text { http://pkuxxj.pku.edu.cn/ } \\
\text { UNPD }\end{array}$ & Gu et al., 2013 \\
\hline Dictionary of natural products & $\begin{array}{l}\text { A structured database holding information on } \\
\text { chemical substances }\end{array}$ & $\begin{array}{l}\text { http://dnp.chemnetbase. } \\
\text { com }\end{array}$ & Petersen et al., 2011 \\
\hline MarinLit & $\begin{array}{l}\text { A database dedicated to marine natural products } \\
\text { research }\end{array}$ & $\begin{array}{l}\text { http://pubs.rsc.org/marin- } \\
\text { lit/ }\end{array}$ & Valli et al., 2013 \\
\hline $\begin{array}{l}\text { Global Natural Products Social Molecular } \\
\text { Networking (GNPS) }\end{array}$ & $\begin{array}{l}\text { A web-based mass spectrometry ecosystem sharing } \\
\text { raw, processed or identified tandem mass (MS/MS) } \\
\text { spectrometry data }\end{array}$ & https://gnps.ucsd.edu & Aron et al., 2020 \\
\hline KNApSAcK & $\begin{array}{l}\text { information on the relationships between } \\
\text { metabolites and their expressing organism(s) }\end{array}$ & $\begin{array}{l}\text { http://kanaya.naist.jp/ } \\
\text { KNApSAcK_Family/ }\end{array}$ & Nakamura et al., 2013 \\
\hline $\begin{array}{l}\text { Natural Product Activityand Species } \\
\text { Source Database (NPASS) }\end{array}$ & $\begin{array}{l}\text { Integrating detailed information of species sources } \\
\text { and biological activities of natural products }\end{array}$ & $\begin{array}{l}\text { http://bidd2.nus.edu.sg/ } \\
\text { NPASS/ }\end{array}$ & Zeng et al., 2018 \\
\hline Ambinter and Greenpharma & Natural products & $\begin{array}{l}\text { http://www.ambinter.com; } \\
\text { http://www.greenpharma. } \\
\text { com }\end{array}$ & - \\
\hline AnalytiCon Discovery & $\begin{array}{l}\text { MEGx-Purified natural products of microbial } \\
\text { and plant origin }\end{array}$ & $\begin{array}{l}\text { http://www.ac-discovery. } \\
\text { com }\end{array}$ & - \\
\hline Chengdu Biopurify Phytochemicals & TCM compounds library & http://www.biopurify.com & - \\
\hline Selleck Chemicals & Natural products & $\begin{array}{l}\text { http://www.selleckchem. } \\
\text { com }\end{array}$ & - \\
\hline TargetMol & Natural compound library & http://www.targetmol.com & - \\
\hline MedChem Express & Natural product library & $\begin{array}{l}\text { http://www.medchemex- } \\
\text { press.com }\end{array}$ & - \\
\hline InterBioScreen & Natural compound collection & http://www.ibscreen.com & - \\
\hline TimTec & Natural product library (NPL) & http://www.timtec.net & - \\
\hline AK Scientific & Natural products & http://www.aksci.com & - \\
\hline $\begin{array}{l}\text { Developmental Therapeutic Program } \\
\text { (DTP)of NCI NIH }\end{array}$ & Natural products Set IV & $\begin{array}{l}\text { http://dtp.cancer.gov/orga- } \\
\text { nization/dscb/obtaining/ } \\
\text { available_plates.htm }\end{array}$ & - \\
\hline INDOFINE Chemical & Natural products, flavonoids, coumarins, etc. & $\begin{array}{l}\text { http://www.indofinechem- } \\
\text { ical.com }\end{array}$ & $\begin{array}{l}\text { INDOFINE Chemical Com- } \\
\text { pany, } 2019\end{array}$ \\
\hline Pharmeks & Screening compounds & http://www.pharmeks.com & - \\
\hline Princeton BioMolecular Research & Macrocycles & $\begin{array}{l}\text { http://www.princetonbio. } \\
\text { com }\end{array}$ & - \\
\hline MicroSource Discovery Systems & Natural products collection (NatProd) & $\begin{array}{l}\text { http://www.msdiscovery. } \\
\text { com }\end{array}$ & - \\
\hline Specs & Natural products & http://www.specs.net & - \\
\hline
\end{tabular}

2001), neural networks (Lo et al., 2018), logistic regression (Wu and Zhao, 2019), naive Bayesian classification (Flach and Lachiche, 2004), binary kernel discrimination (Wu and Zhao, 2019), partial least squares (Mazandu et al., 2011) and random forests (Lo et al., 2018), have contributed to recognizing patterns underlying the relationship between compounds and calculated molecular descriptors or experimental measurements within a large chemo-genomic space (Weaver, 2004). In this space specific activities or classifications for a set of compounds are correlated with their features, thus enabling clustering of similarities among NPlike compounds in multidimensional space (Weaver, 2004). 
For instance, Fang et al. (2017) developed approaches to the development of novel targeted therapies by exploiting the poly-pharmacology of NP. In the new chemical entities (NCE), the initial resource value of substructure associations, drug-target interactions, and drug-substructure associations can be defined as $A_{C S}(i, j), A_{D S}(i, j)$ and $A_{D T}(i, j)$, respectively, The initial resource matrix can be built via these three values for the substructure-drug (or NCE)-target network, and transformed into a final resource matrix by appropriate parameterization. Deep learning and multi-task learning emerge as important in silico methods (Figure 6C and D). For example, Francesco introduced Deep Docking (DD), a novel deep learning platform suitable for docking billions of molecular structures in a rapid yet accurate fashion (Gentile et al., 2020). Using a biomedical knowledge graph, a new potential medication, baricitinib, was identified by BenevolentAI for inhibiting SARS-CoV-2. It has shown promising effects on controlling infection and reducing inflammatory injury, and clinical trials have now started.

\section{Future directions and perspectives}

\section{Challenges facing natural-product-based drug discovery for infectious diseases}

There are many difficulties, related to the availability of efficient and rapid bioassay systems, in screening and identifying conventional NP-based drugs with auspicious antimicrobial activities (Akram et al., 2018). The production of NPs requires reliable supplies of the source material, which may vary by seasonal or through environmental change, or may be lost through extinction or legislation (Tanrikulu et al., 2009). The transition of a natural compound from a "screening hit" through a "drug lead" to a "marketed drug" is associated with demands for increasing amounts of the compound (Atanasov et al., 2015). The traditional approach for NP discovery once relied heavily upon luck (Jensen et al., 2014). The complex chemical structures of bioactive NPs hamper the development of methods for total synthesis or derivation that might be needed for the property optimization of lead candidates (Atanasov et al., 2015). Another major challenge for NP drug discovery is the incompatibility of NPs with HTS (Koehn and Carter, 2005). Adaption and changes in sample preparation and assay designs are necessary to use HTS for the detection of bioactivity in plant extracts and to identify potent pure compounds (Torres et al., 2017). A further challenge is to clarify the precise molecular mechanisms and signaling pathways involved in the bioactivity (Corson and Crews, 2007). Due to high costs, clinical trials of NPs are rarely supported by industry, while the pharmaceutical companies also worry about the patentability of NPs (Atanasov et al., 2015). These issues have all limited the development of NP medicines.
Antibiotic abuse, especially in developing countries, has resulted in the emergence of resistant microbes due to the evolutionary selection pressure imposed by antibiotics (Gwynn et al., 2010). Around 90\%-95\% of Staphylococcus aureus strains worldwide are resistant to penicillin, and $70 \%-80 \%$ of the same strains are methicillin-resistant in many Asian countries (Hemaiswarya et al., 2008). The number of effective therapeutic measures against life-threatening infectious pathogens has fallen dramatically because of the emerging MDR pathogens (Jensen et al., 2014). Therefore, it is extremely urgent for the discovery of novel antibiotics to keep pace with the growing threat of drug resistance (Silber et al., 2016).

The lack of effective therapies and vaccines for various viral infections, and the rapid emergence of new drug-resistant viruses, have produced a growing need for the development of effective new natural-product-based agents to treat viral diseases. New viruses have emerged throughout human history, causing tens of millions of deaths. At present, climate change and globalization have created favorable conditions for the spread of viruses, and in the future, new virus outbreaks may be even more frequent. Therefore, the development of effective antiviral drugs, especially broadspectrum antiviral drugs for conservative targets of different viruses, to fight potential outbreaks of new and re-emerging viruses in the future is a topic of general concern in the academic and industrial communities.

In viruses, the sequences and structures of proteins performing the same functions are often highly similar, such as the spike proteins of SARS-CoV and SARS-CoV-2. These proteins can be used as common targets in the development of antiviral drugs. Among them, representative drugs are Rukobia (fostemsavir, bms-663068), which went on the market in 2020, and the SARS-CoV-2 antibody developed by Eli Lilly and Regeneron Pharmaceuticals, which has been approved for emergency use in the COVID-19 outbreak. However, virus SFTSV is usually under high mutation pressure, so it is difficult to develop broad-spectrum antiviral inhibitors against this target.

At present, only nucleoside analogs targeting viral DNA/ RNA polymerase, such as ribavirin and favipiravir, and compounds targeting host proteins, can be used as broadspectrum antiviral drugs against a large class of viruses. Viruses from the same genus usually contain several highly conserved epitopes, such as TmS and viral protease, which can be further developed as common targets for broadspectrum antiviral drugs. For example, EK1, a virus inhibitor developed for coronavirus before the outbreak of COVID19 , also showed antiviral activity against SARS-CoV-2, indicating the feasibility of designing a broad-spectrum inhibitor for the viruses of the same genus in advance. Therefore, cocktail therapy composed of broad-spectrum viral drugs targeting DNA/RNA polymerase combined with 
two to three kinds of drugs targeting SP transmembrane subunits or viral proteases can be used as a reserve scheme for the treatment of new viruses from the same genus.

Meanwhile, unlike bacteria, viruses have no characteristics in common, such as cell walls. For example, coronavirus and orthomyxovirus have few common components. Therefore, common targets can only be found for certain families of viruses. The natural immune system of the human body plays an important role in antiviral immunity. Different viral infections lead to changes in the expression of various genes in the host, leading to the host presenting different physiological states. After the virus invades the body, it can induce type I and type III interferons (IFNs) to stimulate the body cells to produce hundreds of interferon stimulated genes (ISGs) to combat the virus. The proteins expressed by ISGs can not only directly inhibit the replication of the virus, but also regulate the expression of IFNs, which play indirect antiviral roles. A large number of studies have reported the antiviral effects and related mechanisms of a variety of ISGS proteins and ISGS family proteins. Different ISGs can inhibit the virus at different stages of infection, from invasion to release. Therefore, an herbal medicine targeting human ISG genes can play a broad-spectrum antiviral role by regulating the release of specific ISG genes.

\section{Solutions and development in natural-product-based drug discovery for infectious disease}

New NP screening technologies are currently being exploited to improve hit rates for antibacterial discovery. Lead optimization could be enhanced by the identification of new antibiotic classes with improved tractability, and by expanding the predictability of in vitro safety assays. Implementing multiple screening and target identification strategies is recommended for improving the likelihood of discovering new antibacterial compounds that address unmet needs (Jensen et al., 2014). The intrinsic complexity of NPbased drug discovery necessitates highly integrated interdisciplinary approaches (Atanasov et al., 2015).

NP isolation is laborious and time-consuming, and careful selections of environmental sources of microbes and experimental methods are required to improve the outcomes of isolation procedures (Jensen et al., 2014). The recent rapid increase in genetic information technology has led to novel screenings, and genetic techniques have facilitated the implementation of combinatorial biosynthetic technology and genome mining. The knowledge gained has allowed large numbers of previously unknown molecules to be identified (Akram et al., 2018). Omics analysis, including genomics, transcriptomics, proteomics, metabolomics, and metabolomics, results in the generation of complex multivariate datasets that require computational and chemometric tools for interpretation (Tanrikulu et al., 2009). Genomics has been applied in the identification of NPs and biomarkers, proteomics has been applied to NP validation and biomarker identification, metabolomics and metabonomics have been used in identification studies, and big data has been applied to NP-based drug development and precision medicine as well as target identification and reverse pharmacology (Prachayasittikul et al., 2015).

Continued development of technologies such as genome sequencing, bioinformatics, microbial genomics, metabolic pathway engineering, and synthetic biology are poised to usher in a new age of NP discovery and drug development (Jensen et al., 2014). This is a highly informed approach, in which strains can be prioritized based on a bioinformatic assessment of their biosynthetic potential (Teijaro et al., 2018). The advent of high-throughput genome sequencing techniques has made accessible increasing numbers of microbial genomes which can be evaluated in silico for their capacity to produce secondary metabolites (Hoffmann et al., 2018). Advancements in microbial genomics have shown that, for instance, in Actinobacteria, approximately $90 \%$ of biosynthetic capacity has not been realized (Teijaro et al., 2018; Harvey et al., 2015).

The NPs from various sources, including terrestrial and marine microorganisms, fungi, invertebrates, and plants, each possess unique structural features. These features result from the production of NPs via enzymatic reactions catalyzed by proteins programmed by DNA sequences that differ greatly between the source organisms (Naman et al., 2017). Taxonomic distribution analysis of candidate signals can be especially useful to support the discovery of new NPs (Hoffmann et al., 2018). A study conducted by Pye et al. (2017) demonstrated that most NPs share structural similarity to previously published compounds. Combining the chemotaxonomic method with molecular phylogenetic data would help to select natural species from genera or families known to produce compounds or compound classes associated with certain bioactivities or therapeutic effects in a targeted manner (Ramos Barbosa et al., 2012). Phylogenetic and phytochemical studies have shown that there is a strong phylogenetic signal in the distribution of secondary metabolites in NPs (Saslis-Lagoudakis et al., 2011; Saslis-Lagoudakis et al., 2012). In particular, the exploration of crosscultural ethnomedical patterns within a phylogenetic framework is regarded as a very powerful tool for the identification of highly promising plant groups, when phylogenetically related plant species from very distant regions are found to be used for medical conditions with the same therapeutic aims (Saslis-Lagoudakis et al., 2011; Saslis-Lagoudakis et al., 2012; Atanasov et al., 2015).

Another strategy employed to overcome mechanisms of resistance is the use of a combination of drugs producing synergistic activity against microorganisms (Hemaiswarya et al., 2008). Antibiotics generally target the microbial cell 
wall, but using the approaches described in this review, new therapeutic targets are being identified. The auto-inducer molecules produced by quorum sensing systems are currently targeted by novel compounds to control antibiotic resistance and biofilm formation, quorum sensing, and quorum quenching, and are clearly important as a potential target for natural substances (Mulat et al., 2019). The future development of new antimicrobial agents will rest with those who employ synthetic and semi-synthetic methodology and a further understanding of microbial cell architecture and drug resistance mechanisms (Thomford et al., 2018).

Although this review presents a thorough evaluation of publicly available data, there may be some NP-derived compounds that have been overlooked. Emerging technologies, such as genomics and synthetic biology, are enabling new ways of discovering and utilizing NP-based products. We are entering an exciting era in which the ancient wisdom distilled into the world's traditional herbal medicines can be reinterpreted and exploited through the lens of modern science, demystifying conventional medicines with modern approaches (Li et al., 2017).

Relevant information about 268 NP-based compounds classified into ten groups against 19 selected infectious pathogens was collected for network analysis. The distribution of maximum Tanimoto scores indicated that compounds which inhibit parasites exhibited a low diversity, whereas the chemistries inhibiting bacteria, fungi, and viruses showed more structural diversity. There is a lack of innovation in the methods for discovery of NPs, and more efforts should be paid to exploring novel targets, deciphering mechanisms of action, and discovering bioactive compounds. A total of 331 species of medicinal plants with compounds exhibiting pharmacological activities against four specific infectious pathogens were selected to classify the family sources. NP libraries offer a diversity of chemical components for the discovery of drugs against infectious pathogens. This review summarizes the currently available data on NP-based antimicrobials against refractory infections, to provide information for further discovery and synthesis of drugs acting against infectious pathogens.

Compliance and ethics The author(s) declare that they have no conflict of interest.

Acknowledgements This work was supported by the Scientific and Technological Innovation Project of China Academy of Chinese Medical Sciences (CI2021A04013) and the Fundamental Research Funds for the Central Public Welfare Research Institutes (L2021029). The authors thank Jiqing Zhang, Qin Huang, Qianwen Liu, Dr.Naishi Li, Prof.Haoyu Hu, Dr. Jimeng Zhao, and Dr. Lei Fan for their contributions to this article.

\section{References}

Agamah, F.E., Mazandu, G.K., Hassan, R., Bope, C.D., Thomford, N.E., Ghansah, A., and Chimusa, E.R. (2020). Computational/in silico methods in drug target and lead prediction. Brief Bioinf 21, 1663-1675.

Agarwal, A.K., Xu, T., Jacob, M.R., Feng, Q., Lorenz, M.C., Walker, L.A., and Clark, A.M. (2008). Role of heme in the antifungal activity of the azaoxoaporphine alkaloid sampangine. Eukaryot Cell 7, 387-400.

Aguzzi, A., and Liu, Y. (2017). A role for astroglia in prion diseases. J Exp Med 214, 3477-3479.

Akram, M., Tahir, I.M., Shah, S.M.A., Mahmood, Z., Altaf, A., Ahmad, K., Munir, N., Daniyal, M., Nasir, S., and Mehboob, H. (2018). Antiviral potential of medicinal plants against HIV, HSV, influenza, hepatitis, and coxsackievirus: A systematic review. Phytother Res 32, 811-822.

Alam, N., Hossain, M., Mottalib, M.A., Sulaiman, S.A., Gan, S.H., and Khalil, M.I. (2012). Methanolic extracts of Withania somnifera leaves, fruits and roots possess antioxidant properties and antibacterial activities. BMC Complement Altern Med 12, 175.

Al-Mousawi, A.H., Al-kaabi, S.J., Albaghdadi, A.J.H., Almulla, A.F., Raheem, A., and Algon, A.A.A. (2020). Effect of black grape seed extract (Vitis vinifera) on biofilm formation of methicillin-resistant Staphylococcus aureus and Staphylococcus haemolyticus. Curr Microbiol 77, 238-245.

Alves-Silva, J.M., Piras, A., Porcedda, S., Falconieri, D., Maxia, A., Gonçalves, M.J., Cruz, M.T., and Salgueiro, L. (2020). Chemical characterization and bioactivity of the essential oil from Santolina insularis, a Sardinian endemism. Nat Prod Res doi: 10.1080/ 14786419.2020 .1774764 .

Ambé, A.S.A, Ouattara, D., Tiébré, M.S. Vroh, B.T.A., Zirihi, G.N., and N'Guessan, K.E. (2015). Diversity of medicinal plants used in the traditional treatment of the diarrhea on the markets of Abidjan (Côte d'Ivoire). J Anim Plant Sci 26, 4081-4096.

Analytics, C. (2017). Web of Science. Trust the Difference. Web of Science Fact Book. Available online: http://images.info.science.thomsonreuters. biz/Web/ThomsonReutersScience/\%7Bd6b7faae-3cc2-4186-8985a6ecc8cce1ee\%7D_Crv_WoS_Upsell_Factbook_A4_FA_LR_edits. pdf.

Aron, A.T., Gentry, E.C., McPhail, K.L., Nothias, L.F., Nothias-Esposito, M., Bouslimani, A., Petras, D., Gauglitz, J.M., Sikora, N., Vargas, F., et al. (2020). Reproducible molecular networking of untargeted mass spectrometry data using GNPS. Nat Protoc 15, 1954-1991.

Atanasov, A.G., Waltenberger, B., Pferschy-Wenzig, E.M., Linder, T., Wawrosch, C., Uhrin, P., Temml, V., Wang, L., Schwaiger, S., Heiss, E. H., et al. (2015). Discovery and resupply of pharmacologically active plant-derived natural products: a review. Biotech Adv 33, 1582-1614.

Bachmann, B.O., Van Lanen, S.G., and Baltz, R.H. (2014). Microbial genome mining for accelerated natural products discovery: is a renaissance in the making? J Indust Microbiol Biotech 41, 175-184.

Bahn, Y.S., Kojima, K., Cox, G.M., and Heitman, J. (2005). Specialization of the HOG pathway and its impact on differentiation and virulence of Cryptococcus neoformans. Mol Biol Cell 16, 2285-2300.

Basso, A.M.M., De Castro, R.J.A., de Castro, T.B., Guimarães, H.I., Polez, V.L.P., Carbonero, E.R., Pomin, V.H., Hoffmann, C., Grossi-de-Sa, M. F., Tavares, A.H., et al. (2020). Immunomodulatory activity of $\beta$ glucan-containing exopolysaccharides from Auricularia auricular in phagocytes and mice infected with Cryptococcus neoformans. Med Mycol 58, 227-239.

Bento, A.P., Gaulton, A., Hersey, A., Bellis, L.J., Chambers, J., Davies, M., Krüger, F.A., Light, Y., Mak, L., McGlinchey, S., et al. (2014). The ChEMBL bioactivity database: an update. Nucl Acids Res 42, D1083D1090.

Bindea, G., Mlecnik, B., Hackl, H., Charoentong, P., Tosolini, M., Kirilovsky, A., Fridman, W.H., Pagès, F., Trajanoski, Z., and Galon, J. (2009). ClueGO: a Cytoscape plug-in to decipher functionally grouped gene ontology and pathway annotation networks. Bioinformatics 25, 1091-1093.

Blunt, J.W., Copp, B.R., Keyzers, R.A., Munro, M.H.G., and Prinsep, M.R. (2012). Marine natural products. Nat Prod Rep 29, 144-222.

Boyd, M.R., Hallock, Y.F., Cardellina Ii, J.H., Manfredi, K.P., Blunt, J.W., McMahon, J.B., Buckheit Jr, R.W., Bringmann, G., Schäffer, M., Cragg, G.M., et al. (1994). Anti-HIV michellamines from Ancistrocladus 
korupensis. J Med Chem 37, 1740-1745.

Brown, A.S., and Patel, C.J. (2017). A standard database for drug repositioning. Sci Data 4, 170029.

Burbidge, R., Trotter, M., Buxton, B., and Holden, S. (2001). Drug design by machine learning: support vector machines for pharmaceutical data analysis. Comput Chem 26, 5-14.

Butler, M.S. (2005). Natural products to drugs: natural product derived compounds in clinical trials. Nat Prod Rep 22, 162-195.

Cameron, R.T., Coleman, R.G., Day, J.P., Yalla, K.C., Houslay, M.D., Adams, D.R., Shoichet, B.K., and Baillie, G.S. (2013). Chemical informatics uncovers a new role for moexipril as a novel inhibitor of cAMP phosphodiesterase-4 (PDE4). Biochem Pharmacol 85, 12971305.

Canese, K., and Weis, S. (2013). PubMed: the bibliographic database. In: The NCBI Handbook, 2nd ed. Bethesda: National Center for Biotechnology Information (US).

Cary, D.C., and Peterlin, B.M. (2018). Natural products and HIV/AIDS. AIDS Res Hum Retrov 34, 31-38.

Chang, K.W., Tsai, T.Y., Chen, K.C., Yang, S.C., Huang, H.J., Chang, T.T., Sun, M.F., Chen, H.Y., Tsai, F.J., and Chen, C.Y.C. (2011). iSMART: an integrated cloud computing web server for traditional Chinese medicine for online virtual screening, de novo evolution and drug design. J Biomol Struct Dyn 29, 243-250.

Chen, C.Y. (2011). TCM Database@Taiwan: the world's largest traditional Chinese medicine database for drug screening in silico. PLoS ONE 6, e15939.

Chen, X., Ji, Z.L., and Chen, Y.Z. (2002). TTD: therapeutic target database. Nucleic Acids Res 30, 412-415.

Chen, S.L., Sun, Y., Wan, H.H., Zhang, H., and Zhao, Q.H., (2020). Highlights on the progress of traditional Chinese medicine and natural drugs during 2015-2020 (in Chinese). Acta Pharm Sin 55, 2751-2776.

Chi, Y.M., Zhao, X.Y., and Guo, J.X. (2006). Natural products in drug discovery and development. Nat Prod Res Dev 60, 134-137.

Chisembu, K.C., and Hedimbi, M. (2009). A survey of plants with anti-HIV active compounds and their modes of action. Med J Zambia 36, 178186

Choi, J., Kim, H.J., Jin, X., Lim, H., Kim, S., Roh, I.S., Kang, H.E., No, K. T., and Sohn, H.J. (2018). Application of the fragment molecular orbital method to discover novel natural products for prion disease. Sci Rep 8, 13063.

Clark, R.L., Johnston, B.F., Mackay, S.P., Breslin, C.J., Robertson, M.N., and Harvey, A.L. (2010). The Drug Discovery Portal: a resource to enhance drug discovery from academia. Drug Discov Today 15, 679683.

Consortium, U. (2015). UniProt: a hub for protein information. Nucleic Acids Res 43, D204-D212.

Corsello, S.M., Bittker, J.A., Liu, Z., Gould, J., McCarren, P., Hirschman, J. E., Johnston, S.E., Vrcic, A., Wong, B., Khan, M., et al. (2017). The Drug Repurposing Hub: a next-generation drug library and information resource. Nat Med 23, 405-408.

Corson, T.W., and Crews, C.M. (2007). Molecular understanding and modern application of traditional medicines: triumphs and trials. Cell 130, 769-774.

Cortegiani, A., Ingoglia, G., Ippolito, M., Giarratano, A., and Einav, S. (2020). A systematic review on the efficacy and safety of chloroquine for the treatment of COVID-19. J Crit Care 57, 279-283.

Cragg, G.M., and Newman, D.J. (2013). Natural products: A continuing source of novel drug leads. Biochim Biophys Acta 1830, 3670-3695.

Davis, A.P., Grondin, C.J., Johnson, R.J., Sciaky, D., King, B.L., McMorran, R., Wiegers, J., Wiegers, T.C., and Mattingly, C.J. (2017). The Comparative Toxicogenomics Database: update 2017. Nucleic Acids Res 45, D972-D978.

Deeks, S.G. (2012). HIV: shock and kill. Nature 487, 439-440.

Dvorkin-Camiel, L., and Whelan, J.S. (2008). Tropical American plants in the treatment of infectious diseases. J Diet Suppl 5, 349-372.

Ehrt, C., Brinkjost, T., and Koch, O. (2016). Impact of binding site comparisons on medicinal chemistry and rational molecular design. J
Med Chem 59, 4121-4151.

Fang, J., Wu, Z., Cai, C., Wang, Q., Tang, Y., and Cheng, F. (2017). Quantitative and systems pharmacology. 1. In silico prediction of drugtarget interactions of natural products enables new targeted cancer therapy. J Chem Inf Model 57, 2657-2671.

Fankem, G.O., Fokam Tagne, M.A., Noubissi, P.A., Foyet Fondjo, A., Kamtchouing, I., Ngwewondo, A., Wambe, H., Ngakou Mukam, J., and Kamgang, R. (2019). Antioxidant activity of dichloromethane fraction of Dichrocephala integrifolia in Salmonella typhi-infected rats. J Integr Med 17, 438-445.

Ferreira, N.C., Marques, I.A., Conceição, W.A., Macedo, B., Machado, C. S., Mascarello, A., Chiaradia-Delatorre, L.D., Yunes, R.A., Nunes, R.J., Hughson, A.G., et al. (2014). Anti-prion activity of a panel of aromatic chemical compounds: in vitro and in silico approaches. PLoS ONE 9, e84531.

Flach, P.A., and Lachiche, N. (2004). Naive Bayesian classification of structured data. Mach Learn 57, 233-269.

Gaulton, A., Hersey, A., Nowotka, M., Bento, A.P., Chambers, J., Mendez, D., Mutowo, P., Atkinson, F., Bellis, L.J., Cibrián-Uhalte, E., et al. (2016). The ChEMBL database in 2017. Nucleic Acids Res 45, D945D954.

Gentile, F., Agrawal, V., Hsing, M., Ton, A.T., Ban, F., Norinder, U., Gleave, M.E., and Cherkasov, A. (2020). Deep Docking: a deep learning platform for augmentation of structure based drug discovery. ACS Cent Sci 6, 939-949.

Gu, J., Gui, Y., Chen, L., Yuan, G., Lu, H.Z., and Xu, X. (2013). Use of natural products as chemical library for drug discovery and network pharmacology. PLoS ONE 8, e62839.

Gwynn, M.N., Portnoy, A., Rittenhouse, S.F., and Payne, D.J. (2010). Challenges of antibacterial discovery revisited. Ann New York Acad Sci 1213, 5-19.

Häcker, G. (2018). Apoptosis in infection. Microbes Infection 20, 552-559.

Hamann, M.T., Scheuer, P.J., and Kelly-Borges, M. (1993). Biogenetically diverse, bioactive constituents of a sponge, order Verongida: bromotyramines and sesquiterpene-shikimate derived metabolites. J Org Chem 58, 6565-6569.

Han, C., and Guo, J. (2012). Antibacterial and anti-inflammatory activity of traditional Chinese herb pairs, Angelica sinensis and Sophora flavescens. Inflammation 35, 913-919.

Han, X., Chen, C., Yan, Q., Jia, L., Taj, A., and Ma, Y. (2019). Action of dicumarol on glucosamine-1-phosphate acetyltransferase of GlmU and Mycobacterium tuberculosis. Front Microbiol 10, 1799.

Hartkoorn, R.C., Sala, C., Neres, J., Pojer, F., Magnet, S., Mukherjee, R., Uplekar, S., Boy-Röttger, S., Altmann, K.H., and Cole, S.T. (2012). Towards a new tuberculosis drug: pyridomycin — nature's isoniazid. EMBO Mol Med 4, 1032-1042.

Harvey, A.L., Edrada-Ebel, R.A., and Quinn, R.J. (2015). The reemergence of natural products for drug discovery in the genomics era. Nat Rev Drug Discov 14, 111-129.

He, M., Yan, X., Zhou, J., and Xie, G. (2001). Traditional Chinese medicine database and application on the web. J Chem Inf Comput Sci 41, 273277.

Hecker, N., Ahmed, J., von Eichborn, J., Dunkel, M., Macha, K., Eckert, A., Gilson, M.K., Bourne, P.E., and Preissner, R. (2012). SuperTarget goes quantitative: update on drug-target interactions. Nucleic Acids Res 40, D1113-D1117.

Hemaiswarya, S., Kruthiventi, A.K., and Doble, M. (2008). Synergism between natural products and antibiotics against infectious diseases. Phytomedicine 15, 639-652.

Himmelstein, D.S., Lizee, A., Hessler, C., Brueggeman, L., Chen, S.L., Hadley, D., Green, A., Khankhanian, P., and Baranzini, S.E. (2017). Systematic integration of biomedical knowledge prioritizes drugs for repurposing. eLife 6, e26726.

Hoffmann, M.F., Preissner, S.C., Nickel, J., Dunkel, M., Preissner, R., and Preissner, S. (2014). The Transformer database: biotransformation of xenobiotics. Nucl Acids Res 42, D1113-D1117.

Hoffmann, T., Krug, D., Bozkurt, N., Duddela, S., Jansen, R., Garcia, R., 
Gerth, K., Steinmetz, H., and Müller, R. (2018). Correlating chemical diversity with taxonomic distance for discovery of natural products in myxobacteria. Nat Commun 9, 803.

Howard, K.C., Dennis, E.K., Watt, D.S., and Garneau-Tsodikova, S. (2020). A comprehensive overview of the medicinal chemistry of antifungal drugs: perspectives and promise. Chem Soc Rev 49, 24262480.

Huang, R., Southall, N., Wang, Y., Yasgar, A., Shinn, P., Jadhav, A., Nguyen, D.T., and Austin, C.P. (2011). The NCGC pharmaceutical collection: a comprehensive resource of clinically approved drugs enabling repurposing and chemical genomics. Sci Transl Med 3, 80 ps 16.

Huerta-Reyes, M., Basualdo, M.D.C., Abe, F., Jimenez-Estrada, M., Soler, C., and Reyes-Chilpa, R. (2004). HIV-1 inhibitory compounds from Calophyllum brasiliense leaves. Biol Pharm Bull 27, 1471-1475.

Ichimura, T., Watanabe, O., and Maruyama, S. (1998). Inhibition of HIV-1 protease by water-soluble lignin-like substance from an edible mushroom, Fuscoporia obliqua. Biosci Biotechnol Biochem 62, 575577.

Imberdis, T., Heeres, J.T., Yueh, H., Fang, C., Zhen, J., Rich, C.B., Glicksman, M., Beeler, A.B., and Harris, D.A. (2016). Identification of anti-prion compounds using a novel cellular assay. J Biol Chem 291, 26164-26176.

Ishibashi, D., Nakagaki, T., Ishikawa, T., Atarashi, R., Watanabe, K., Cruz, F.A., Hamada, T., and Nishida, N. (2016). Structure-based drug discovery for prion disease using a novel binding simulation. Ebiomedicine 9, 238-249.

Ishibashi, M., Tsuda, M., Ohizumi, Y., Sasaki, T., and Kobayashi, J. (1991). Purealidin A, a new cytotoxic bromotyrosine-derived alkaloid from the Okinawan marine spongePsammaplysilla purea. Experientia 47, 299300.

Jatsa, H.B., Kenfack, C.M., Simo, D.N., Feussom, N.G., Nkondo, E.T., Tchuem Tchuente, L.A., Tsague, C.D., Dongo, E., and Kamtchouing, P. (2015). Schistosomicidal, hepatoprotective and antioxidant activities of the methanolic fraction from Clerodendrum umbellatum Poir leaves aqueous extract in Schistosoma mansoni infection in mice. BMC Complement Altern Med 15, 248.

Jennings, L.K., Ahmed, I., Munn, A.L., and Carroll, A.R. (2018). Yeastbased screening of natural product extracts results in the identification of prion inhibitors from a marine sponge. Prion 12, 234-244.

Jensen, P.R., Chavarria, K.L., Fenical, W., Moore, B.S., and Ziemert, N. (2014). Challenges and triumphs to genomics-based natural product discovery. J Ind Microbiol Biotech 41, 203-209.

Jo, S., Kim, H., Kim, S., Shin, D.H., and Kim, M.S. (2019). Characteristics of flavonoids as potent MERS-CoV 3C-like protease inhibitors. Chem Biol Drug Des 94, 2023-2030.

Kaneda, Y., Torii, M., Tanaka, T., and Aikawa, M. (1991). In vitro effects of berberine sulphate on the growth and structure of Entamoeba histolytica, Giardia lamblia and Trichomonas vaginalis. Ann Trop Med Parasitol 85, 417-425.

Kinghorn, A.D., Falk, H., Gibbons, S., Kobayashi, J., Asakawa, Y., and Liu, J.K. (2019). Progress in the Chemistry of Organic Natural Products-Cheminformatics in Natural Product-Based Drug Discovery. Cham: Springer International Publishing.

Kanehisa, M., and Goto, S. (2000). KEGG: Kyoto Encyclopedia of Genes and Genomes. Nucleic Acids Res 28, 27-30.

Keenan, A.B., Jenkins, S.L., Jagodnik, K.M., Koplev, S., He, E., Torre, D., Wang, Z., Dohlman, A.B., Silverstein, M.C., Lachmann, A., et al. (2018). The Library of Integrated Network-based Cellular Signatures NIH Program: system-level cataloging of human cells response to perturbations. Cell Syst 6, 13-24.

Keiser, M.J., Setola, V., Irwin, J.J., Laggner, C., Abbas, A.I., Hufeisen, S.J., Jensen, N.H., Kuijer, M.B., Matos, R.C., Tran, T.B., et al. (2009). Predicting new molecular targets for known drugs. Nature 462, 175181.

Kim, H.J., Woo, E.R., Shin, C.G., and Park, H. (1998). A new flavonol glycoside gallate ester from Acer okamotoanum and its inhibitory activity against human immunodeficiency virus-1 (HIV-1) integrase. J Nat Prod 61, 145-148.

Kim, S., Thiessen, P.A., Bolton, E.E., Chen, J., Fu, G., Gindulyte, A., Han, L., He, J., He, S., Shoemaker, B.A., et al. (2016). PubChem substance and compound databases. Nucleic Acids Res 44, D1202-D1213.

Kirchmair, J., Göller, A.H., Lang, D., Kunze, J., Testa, B., Wilson, I.D., Glen, R.C., and Schneider, G. (2015). Predicting drug metabolism: experiment and/or computation? Nat Rev Drug Discov 14, 387-404.

Kitazato, K., Wang, Y., and Kobayashi, N. (2007). Viral infectious disease and natural products with antiviral activity. Drug Discov Ther 1, 14-22.

Kitchen, D.B., Decornez, H., Furr, J.R., and Bajorath, J. (2004). Docking and scoring in virtual screening for drug discovery: methods and applications. Nat Rev Drug Discov 3, 935-949.

Klöhn, P.C., Stoltze, L., Flechsig, E., Enari, M., and Weissmann, C. (2003). A quantitative, highly sensitive cell-based infectivity assay for mouse scrapie prions. Proc Natl Acad Sci USA 100, 11666-11671.

Kocisko, D.A., Baron, G.S., Rubenstein, R., Chen, J., Kuizon, S., and Caughey, B. (2003). New inhibitors of scrapie-associated prion protein formation in a library of 2,000 drugs and natural products. J Virol 77, 10288-10294.

Koehn, F.E., and Carter, G.T. (2005). The evolving role of natural products in drug discovery. Nat Rev Drug Discov 4, 206-220.

Kong, D.X., Guo, M.Y., Xiao, Z.H., Chen, L.L., and Zhang, H.Y. (2011). Historical variation of structural novelty in a natural product library. Chem Biodivers 8, 1968-1977.

Kuhn, M., Letunic, I., Jensen, L.J., and Bork, P. (2016). The SIDER database of drugs and side effects. Nucleic Acids Res 44, D1075D1079.

Laconi, S., Madeddu, M.A., and Pompei, R. (2014). Autophagy activation and antiviral activity by a licorice triterpene. Phytother Res 28,1890 1892.

Law, V., Knox, C., Djoumbou, Y., Jewison, T., Guo, A.C., Liu, Y., Maciejewski, A., Arndt, D., Wilson, M., Neveu, V., et al. (2014). DrugBank 4.0: shedding new light on drug metabolism. Nucl Acids Res 42, D1091-D1097.

Letunic, I., and Bork, P. (2016). Interactive tree of life (iTOL) v3: an online tool for the display and annotation of phylogenetic and other trees. Nucleic Acids Res 44, W242-W245.

Li, B., Ma, C., Zhao, X., Hu, Z., Du, T., Xu, X., Wang, Z., and Lin, J. (2018). YaTCM: Yet another Traditional Chinese Medicine Database for Drug Discovery. Comput Struct Biotech J 16, 600-610.

Li, F.S., and Weng, J.K. (2017). Demystifying traditional herbal medicine with modern approach. Nat Plants 3, 17109.

Li, H.Y., Sun, N.J., Kashiwada, Y., Sun, L., Snider, J.V., Cosentino, L.M., and Lee, K.H. (1993). Anti-AIDS Agents, 9. Suberosol, a New $C_{31}$ lanostane-type triterpene and anti-HIV principle from Polyalthia suberosa. J Nat Prod 56, 1130-1133.

Li, L., Wei, W., Jia, W.J., Zhu, Y., Zhang, Y., Chen, J.H., Tian, J., Liu, H., He, Y.X., and Yao, X. (2017). Discovery of small molecules binding to the normal conformation of prion by combining virtual screening and multiple biological activity evaluation methods. J Comput Aided Mol Des 31, 1053-1062.

Lin, Y.M., Anderson, H., Flavin, M.T., Pai, Y.H.S., Mata-Greenwood, E., Pengsuparp, T., Pezzuto, J.M., Schinazi, R.F., Hughes, S.H., and Chen, F.C. (1997). In vitro anti-HIV activity of biflavonoids isolated from Rhus succedanea and Garcinia multiflora. J Nat Prod 60, 884-888.

Liu, B., and Zhou, J. (2005). SARS-CoV protease inhibitors design using virtual screening method from natural products libraries. J Comput Chem 26, 484-490.

Liu, T.B., Perlin, D.S., and Xue, C. (2012). Molecular mechanisms of cryptococcal meningitis. Virulence 3, 173-181.

Lo, Y.C., Rensi, S.E., Torng, W., and Altman, R.B. (2018). Machine learning in chemoinformatics and drug discovery. Drug Discov Today 23, 1538-1546.

Lounkine, E., Keiser, M.J., Whitebread, S., Mikhailov, D., Hamon, J., Jenkins, J.L., Lavan, P., Weber, E., Doak, A.K., Côté, S., et al. (2012). Large-scale prediction and testing of drug activity on side-effect targets. 
Nature 486, 361-367.

Ludovico, P., Sansonetty, F., and Côrte-Real, M. (2001). Assessment of mitochondrial membrane potential in yeast cell populations by flow cytometry. Microbiology 147, 3335-3343.

Lung, J., Lin, Y.S., Yang, Y.H., Chou, Y.L., Shu, L.H., Cheng, Y.C., Liu, H. T., and $\mathrm{Wu}, \mathrm{C} . Y$. (2020). The potential chemical structure of anti-SARSCoV-2 RNA-dependent RNA polymerase. J Med Virol 92, 693-697.

Luo, L., Jiang, J., Wang, C., Fitzgerald, M., Hu, W., Zhou, Y., Zhang, H., and Chen, S. (2020). Analysis on herbal medicines utilized for treatment of COVID-19. Acta Pharm Sin B 10, 1192-1204.

Ma, Y. (1981). Conception on infectious diseases from the perspective of traditional medicine. J Tradit Chin Med 3, 1-3.

Malachowski, A.N., Yosri, M., Park, G., Bahn, Y.S., He, Y., and Olszewski, M.A. (2016). Systemic approach to virulence gene network analysis for gaining new insight into cryptococcal virulence. Front Microbiol 7, 1-4.

March-Vila, E., Pinzi, L., Sturm, N., Tinivella, A., Engkvist, O., Chen, H., and Rastelli, G. (2017). On the integration of in silico drug design methods for drug repurposing. Front Pharmacol 8.

Matsuda, Y., and Abe, I. (2016). Biosynthesis of fungal meroterpenoids. Nat Prod Rep 33, 26-53.

Mazandu, G.K., Opap, K., and Mulder, N.J. (2011). Contribution of microarray data to the advancement of knowledge on the Mycobacterium tuberculosis interactome: use of the random partial least squares approach. Infect Genet Evol 11, 181-189.

Min, B.S., Jung, H.J., Lee, J.S., Kim, Y.H., Bok, S.H., Ma, C.M., Nakamura, N., Hattori, M., and Bae, K. (1999). Inhibitory effect of triterpenes from Crataegus pinatifida on HIV-I protease. Planta Med 65, 374-375.

Morisset, S., Rouleau, A., Ligneau, X., Gbahou, F., Tardivel-Lacombe, J., Stark, H., Schunack, W., Ganellin, C.R., Schwartz, J.C., and Arrang, J. M. (2000). High constitutive activity of native H3 receptors regulates histamine neurons in brain. Nature 408, 860-864.

Mujawar, S., Gatherer, D., and Lahiri, C. (2018). Paradigm shift in drug repurposing from phenalenone to phenaleno-furanone to combat multidrug resistant Salmonella enterica serovar typhi. Front Cell Infect Microbiol 8.

Mulat, M., Pandita, A., and Khan, F. (2019). Medicinal plant compounds for combating the multi-drug resistant pathogenic bacteria: a review. Curr Pharm Biotechnol 20, 183-196.

Müller, C., Schulte, F.W., Lange-Grünweller, K., Obermann, W., Madhugiri, R., Pleschka, S., Ziebuhr, J., Hartmann, R.K., and Grünweller, A. (2018). Broad-spectrum antiviral activity of the eIF4A inhibitor silvestrol against corona- and picornaviruses. Antiviral Res $150,123-129$.

Nakamura, K., Shimura, N., Otabe, Y., Hirai-Morita, A., Nakamura, Y., Ono, N., Ul-Amin, M.A., and Kanaya, S. (2013). KNApSAcK-3D: a three-dimensional structure database of plant metabolites. Plant Cell Physiol 54, e4.

Naman, C.B., Leber, C.A., and Gerwick, W.H. (2017). Chapter 5. Modern natural products drug discovery and its relevance to biodiversity conservation. In: Microbial Resources. New York: Academic Press. 103120 .

Newman, D.J., and Cragg, G.M. (2016). Natural products as sources of new drugs from 1981 to 2014. J Nat Prod 79, 629-661.

Nguyen, D.T., Mathias, S., Bologa, C., Brunak, S., Fernandez, N., Gaulton, A., Hersey, A., Holmes, J., Jensen, L.J., Karlsson, A., et al. (2017). Pharos: collating protein information to shed light on the druggable genome. Nucleic Acids Res 45, D995-D1002.

Ntie-Kang, F., Zofou, D., Babiaka, S.B., Meudom, R., Scharfe, M., Lifongo, L.L., Mbah, J.A., Mbaze, L.M., Sippl, W., and Efange, S.M.N. (2013). AfroDb: a select highly potent and diverse natural product library from African medicinal plants. PLoS ONE 8, e78085.

Pang, R., Tao, J.Y., Zhang, S.L., Chen, K.L., Zhao, L., Yue, X., Wang, Y.F., Ye, P., Zhu, Y., and Wu, J.G. (2011). Ethanol extract from ampelopsis sinica root exerts anti-hepatitis B virus activity via inhibition of $\mathrm{p} 53$ pathway in vitro. Evid Based Complement Alternat Med 2011, 1-7.

Panthong, P., Bunluepuech, K., Boonnak, N., Chaniad, P., Pianwanit, S.,
Wattanapiromsakul, C., and Tewtrakul, S. (2015). Anti-HIV-1 integrase activity and molecular docking of compounds from Albizia procera bark. Pharm Biol 53, 1861-1866.

Park, B.J., Wannemuehler, K.A., Marston, B.J., Govender, N., Pappas, P.G., and Chiller, T.M. (2009). Estimation of the current global burden of cryptococcal meningitis among persons living with HIV/AIDS. AIDS 23, 525-530.

Pascolutti, M., Campitelli, M., Nguyen, B., Pham, N., Gorse, A.D., and Quinn, R.J. (2015). Capturing nature's diversity. PLoS ONE 10, e0120942.

Patwardhan, B. (2005). Ethnopharmacology and drug discovery. J Ethnopharmacol 100, 50-52.

Pavan, S., Rommel, K., Mateo Marquina, M.E., Höhn, S., Lanneau, V., and Rath, A. (2017). Clinical practice guidelines for rare diseases: the orphanet database. PLoS ONE 12, e0170365.

Peng, X., and Qiu, M. (2018). Meroterpenoids from Ganoderma species: a review of last five years. Nat Prod Bioprospect 8, 137-149.

Petersen, R.K., Christensen, K.B., Assimopoulou, A.N., Fretté, X., Papageorgiou, V.P., Kristiansen, K., and Kouskoumvekaki, I. (2011). Pharmacophore-driven identification of PPAR $\gamma$ agonists from natural sources. J Comput Aided Mol Des 25, 107-116.

Pham, J.V., Yilma, M.A., Feliz, A., Majid, M.T., Maffetone, N., Walker, J. R., Kim, E., Cho, H.J., Reynolds, J.M., Song, M.C., et al. (2019). A review of the microbial production of bioactive natural products and biologics. Front Microbiol 10, 1404.

Prachayasittikul, V., Worachartcheewan, A., Shoombuatong, W., Songtawee, N., Simeon, S., Prachayasittikul, V., and Nantasenamat, C. (2015). Computer-aided drug design of bioactive natural products. Curr Top Med Chem 15, 1780-1800.

Pye, C.R., Bertin, M.J., Lokey, R.S., Gerwick, W.H., and Linington, R.G. (2017). Retrospective analysis of natural products provides insights for future discovery trends. Proc Natl Acad Sci USA 114, 5601-5606.

Qian, H., and Jin, Y. (2016). An updated megaphylogeny of plants, a tool for generating plant phylogenies and an analysis of phylogenetic community structure. J Plant Ecol 9, 233-239.

Ramos Barbosa, W.L., do Nascimento, M.S., Nascimento Pinto, L., do Costa Maia, F.L., Ataide Sousa, A.J., Silva Junior, J.O.C., Monteiro, M.M., and de Oliveira, D.R. (2012). Selecting medicinal plants for development of phytomedicine and use in primary health care. In: Rasooli, I., ed. Bioactive Compounds in Phytomedicine. London: IntechOpen.

Reddy, K.H., Sharma, P.V.G.K., and Reddy, O.V.S. (2010). A comparative in vitro study on antifungal and antioxidant activities of Nervilia aragoana and Atlantia monophylla. Pharma Biol 48, 595-602.

Reller, L.B., Weinstein, M.P., Procop, G.W., and Wilson, M. (2001). Infectious disease pathology. Clin Infect Dis 32, 1589-1601.

Richardson, P., Griffin, I., Tucker, C., Smith, D., Oechsle, O., Phelan, A., Rawling, M., Savory, E., and Stebbing, J. (2020). Baricitinib as potential treatment for $2019-\mathrm{nCoV}$ acute respiratory disease. Lancet 395, e30-e31.

Rodgers, G., Austin, C., Anderson, J., Pawlyk, A., Colvis, C., Margolis, R., and Baker, J. (2018). Glimmers in illuminating the druggable genome. Nat Rev Drug Discov 17, 301-302.

Rosén, J., Gottfries, J., Muresan, S., Backlund, A., and Oprea, T.I. (2009). Novel chemical space exploration via natural products. J Med Chem 52, 1953-1962.

Ru, J., Li, P., Wang, J., Zhou, W., Li, B., Huang, C., Li, P., Guo, Z., Tao, W., Yang, Y., et al. (2014). TCMSP: a database of systems pharmacology for drug discovery from herbal medicines. J Cheminform 6, 13 .

Saag, M.S., Graybill, R.J., Larsen, R.A., Pappas, P.G., Perfect, J.R., Powderly, W.G., Sobel, J.D., and Dismukes, W.E. (2000). Practice guidelines for the management of cryptococcal disease. Clin Infect Dis 30, 710-718.

Salam, A.M., and Quave, C.L. (2018). Opportunities for plant natural products in infection control. Curr Opin Microbiol 45, 189-194.

Samie, S., Trollope, K.M., Joubert, L.M., Makunga, N.P., and Volschenk, H. (2019). The antifungal and Cryptococcus neoformans virulence 
attenuating activity of Pelargonium sidoides extracts. J Ethnopharmacol $235,122-132$.

Saslis-Lagoudakis, C.H., Klitgaard, B.B., Forest, F., Francis, L., Savolainen, V., Williamson, E.M., and Hawkins, J.A. (2011). The use of phylogeny to interpret cross-cultural patterns in plant use and guide medicinal plant discovery: an example from Pterocarpus (Leguminosae). PLoS ONE 6, e22275.

Saslis-Lagoudakis, C.H., Savolainen, V., Williamson, E.M., Forest, F., Wagstaff, S.J., Baral, S.R., Watson, M.F., Pendry, C.A., and Hawkins, J. A. (2012). Phylogenies reveal predictive power of traditional medicine in bioprospecting. Proc Natl Acad Sci USA 109, 15835-15840.

Schuster, D., Kern, L., Hristozov, D.P., Terfloth, L., Bienfait, B., Laggner, C., Kirchmair, J., Grienke, U., Wolber, G., Langer, T., et al. (2010). Applications of integrated data mining methods to exploring natural product space for acetylcholinesterase inhibitors. Comb Chem High Throughput Screen 13, 54-66.

Shannon, P., Markiel, A., Ozier, O., Baliga, N.S., Wang, J.T., Ramage, D., Amin, N., Schwikowski, B., and Ideker, T. (2003). Cytoscape: a software environment for integrated models of biomolecular interaction networks. Genome Res 13, 2498-2504.

Shen, J., Xu, X., Cheng, F., Liu, H., Luo, X., Shen, J., Chen, K., Zhao, W., Shen, X., and Jiang, H. (2003). Virtual screening on natural products for discovering active compounds and target information. Curr Med Chem 10, 2327-2342

Silber, J., Kramer, A., Labes, A., and Tasdemir, D. (2016). From discovery to production: biotechnology of marine fungi for the production of new antibiotics. Mar Drugs 14, 137.

Silva, H.A.M.F., Sá, J.L.F., Siqueira, W.N., Lima, M.V., Martins, M.C.B., Aires, A.L., Albuquerque, M.C.P.A., Falcão, E.P.S., Buril, M.L.L., Pereira, E.C., et al. (2019). Toxicological effects of Ramalina aspera (lichen) on Biomphalaria glabrata snails and Schistosoma mansoni cercariae. Acta Trop 196, 172-179.

Singh, D., Narayanamoorthy, S., Gamre, S., Majumdar, A.G., Goswami, M., Gami, U., Cherian, S., and Subramanian, M. (2018). Hydroxychavicol, a key ingredient of Piper betle induces bacterial cell death by DNA damage and inhibition of cell division. Free Radic Biol Med 120, 62-71.

Sloan, D.J., and Parris, V. (2014). Cryptococcal meningitis: epidemiology and therapeutic options. Clin Epidemiol 6, 169-182.

Sohrabi, C., Alsafi, Z., O'Neill, N., Khan, M., Kerwan, A., Al-Jabir, A., Iosifidis, C., and Agha, R. (2020). World Health Organization declares global emergency: a review of the 2019 novel coronavirus (COVID-19). Int J Surg 76, 71-76.

Su, F., Zhao, Z., Ma, S., Wang, R., Li, Y., Liu, Y., Li, Y., Li, L., Qu, J., and Yu, S. (2017). Cnidimonins A-C, Three types of hybrid dimer from Cnidium monnieri: structural elucidation and semisynthesis. Org Lett 19, 4920-4923.

Su, H.X., Yao, S., Zhao, W.F., Li, M.J., Liu, J., Shang, W.J., Xie, H., Ke, C. Q., Hu, H.C., Gao, M.N., et al. (2020). Anti-SARS-CoV-2 activities in vitro of Shuanghuanglian preparations and bioactive ingredients. Acta Pharmacol Sin 41, 1167-1177.

Szklarczyk, D., Santos, A., von Mering, C., Jensen, L.J., Bork, P., and Kuhn, M. (2016). STITCH 5: augmenting protein-chemical interaction networks with tissue and affinity data. Nucleic Acids Res 44, D380D384.

Tanrikulu, Y., Rau, O., Schwarz, O., Proschak, E., Siems, K., Müller-Kuhrt, L., Schubert-Zsilavecz, M., and Schneider, G. (2009). Structure-based pharmacophore screening for Natural-Product-Derived PPAR $\gamma$ agonists. Chembiochem 10, 75-78.

Teijaro, C.N., Adhikari, A., and Shen, B. (2018). Challenges and opportunities for natural product discovery, production, and engineering in native producers versus heterologous hosts. J Ind Microbiol Biotech 46, 433-444.

The R Core Team. (2013). R: A Language and Environment for Statistical Computing. R Foundation for Statistical Computing. https://www.Rproject.org/.

Thomford, N.E., Senthebane, D.A., Rowe, A., Munro, D., Seele, P.,
Maroyi, A., and Dzobo, K. (2018). Natural products for drug discovery in the 21st century: innovations for novel drug discovery. Int J Mol Sci 19,1578 .

Tilvi, S., Rodrigues, C., Naik, C.G., Parameswaran, P.S., and Wahidhulla, S. (2004). New bromotyrosine alkaloids from the marine sponge Psammaplysilla purpurea. Tetrahedron 60, 10207-10215.

Torrent, J., Vilchez-Acosta, A., Muñoz-Torrero, D., Trovaslet, M., Nachon, F., Chatonnet, A., Grznarova, K., Acquatella-Tran Van Ba, I., Le Goffic, R., Herzog, L., et al. (2015). Interaction of prion protein with acetylcholinesterase: potential pathobiological implications in prion diseases. Acta Neuropathol Commun 3, 1-8.

Torres, C.A., Nuñez, M.B., Isla, M.I., Castro, M.P., Gonzalez, A.M., and Zampini, I.C. (2017). Antibacterial synergism of extracts from climbers belonging to Bignoniaceae family and commercial antibiotics against multi-resistant bacteria. J Herbal Med 8, 24-30.

Trosset, J.Y., and Cavé, C. (2019). In silico drug-target profiling. In: Moll, J., and Carotta, S., eds. Target Identification and Validation in Drug Discovery. Methods in Molecular Biology. New York: Humana Press. 89-103.

Tsai, T.Y., Chang, K.W., and Chen, C.Y.C. (2011). iScreen: world's first cloud-computing web server for virtual screening and de novo drug design based on TCM database@Taiwan. J Comput Aided Mol Des 25, 525-531.

Tsukamoto, S., Kato, H., Hirota, H., and Fusetani, N. (1996). Ceratinamine: an unprecedented antifouling cyanoformamide from the marine sponge Pseudoceratina purpurea. J Org Chem 61, 2936-2937.

Valli, M., dos Santos, R.N., Figueira, L.D., Nakajima, C.H., CastroGamboa, I., Andricopulo, A.D., and Bolzani, V.S. (2013). Development of a natural products database from the biodiversity of Brazil. J Nat Prod 76, 439-444.

Veras, L.M., Guimaraes, M.A., Campelo, Y.D., Vieira, M.M., Nascimento, C., Lima, D.F., Vasconcelos, L., Nakano, E., Kuckelhaus, S.S., Batista, M.C., et al. (2012). Activity of epiisopiloturine against Schistosoma mansoni. Curr Med Chem 19, 2051-2058.

Viegas, F.P.D., de Castro, A.T., Castro, A.P., Siqueira, Í., Rosa, W., Espuri, P.F., Coelho, L.F.L., Marques, M.J., and Soares, M.G. (2017). In vitro schistosomicidal activity of the crude extract, fractions and Primin, the major active benzoquinone constituent from the leaves of Miconia willdenowii (Melastomaceae). South Afr J Bot 111, 365-370.

Vine, R. (2006). Google scholar. J Med Libr Assoc 94, 97-99.

Wagner, A.H., Coffman, A.C., Ainscough, B.J., Spies, N.C., Skidmore, Z. L., Campbell, K.M., Krysiak, K., Pan, D., McMichael, J.F., Eldred, J. M., et al. (2016). DGIdb 2.0: mining clinically relevant drug-gene interactions. Nucleic Acids Res 44, D1036-D1044.

Wang, K. (2008). New target and development direction of chronic hepatitis B treatment (in Chinese). Chin J Front Med 1, 11-14.

Wang, J., Chen, F., Liu, Y., Liu, Y., Li, K., Yang, X., Liu, S., Zhou, X., and Yang, J. (2018). Spirostaphylotrichin X from a marine-derived fungus as an anti-influenza agent targeting RNA polymerase PB2. J Nat Prod $81,2722-2730$.

Wang, Y.M., and Shi, L.L. (2012). Comparison among the search platforms of Wanfang Database, CNKI database and VIP database (in Chinese). Shanxi Libr J 6, 22-34.

Wangchuk, P., Pearson, M.S., Giacomin, P.R., Becker, L., Sotillo, J., Pickering, D., Smout, M.J., and Loukas, A. (2016). Compounds derived from the bhutanese daisy, ajania nubigena, demonstrate dual anthelmintic activity against schistosoma mansoni and trichuris muris. PLoS Negl Trop Dis 10, e0004908.

Weaver, D.C. (2004). Applying data mining techniques to library design, lead generation and lead optimization. Curr Opin Chem Biol 8, 264270.

Winder, M. (1988). Paul U. Unschuld, Medicine in China. A history of pharmaceutics. Berkeley, Los Angeles and London, University of California Press, 1986, 4to, pp. xiii, 366, illus., £40.50. Med Hist 32, 345.

Wishart, D., Arndt, D., Pon, A., Sajed, T., Guo, A.C., Djoumbou, Y., Knox, C., Wilson, M., Liang, Y., Grant, J., et al. (2015). T3DB: the toxic 
exposome database. Nucleic Acids Res 43, D928-D934.

Wu, J., and Zhao, Y. (2019). Machine learning technology in the application of genome analysis: A systematic review. Gene 705, 149156.

Wu, L., Ai, N., Liu, Y., Wang, Y., and Fan, X. (2013). Relating anatomical therapeutic indications by the ensemble similarity of drug sets. J Chem Inf Model 53, 2154-2160.

Xia, J., Wright, J., and Adams, C.E. (2008). Five large Chinese biomedical bibliographic databases: accessibility and coverage. Health Inf Libr J $25,55-61$.

Xu, H.X., Zeng, F.Q., Wan, M., and Sim, K.Y. (1996). Anti-HIV triterpene acids from Geum japonicum. J Nat Prod 59, 643-645.

Xue, R., Fang, Z., Zhang, M., Yi, Z., Wen, C., and Shi, T. (2013). TCMID: Traditional Chinese Medicine integrative database for herb molecular mechanism analysis. Nucleic Acids Res 41, D1089-D1095.

Yu, M.S., Lee, J., Lee, J.M., Kim, Y., Chin, Y.W., Jee, J.G., Keum, Y.S., and Jeong, Y.J. (2012). Identification of myricetin and scutellarein as novel chemical inhibitors of the SARS coronavirus helicase, nsP13. Bioorg Med Chem Lett 22, 4049-4054.

Yao, C. (2010). Inner Cannon of Yellow Emperor (Huang Di Nei Jing) (in Chinese). Beijing: Zhonghua Book Company.

Zaragoza, O., Telzak, A., Bryan, R.A., Dadachova, E., and Casadevall, A. (2006). The polysaccharide capsule of the pathogenic fungus Cryptococcus neoformans enlarges by distal growth and is rearranged during budding. Mol Microbiol 59, 67-83.

Zeng, X., Zhang, P., He, W., Qin, C., Chen, S., Tao, L., Wang, Y., Tan, Y., Gao, D., Wang, B., et al. (2018). Npass: natural product activity and species source database for natural product research, discovery and tool development. Nucleic Acids Res 46, D1217-D1222.

Zhang, L., and Wang, C.C. (2014). Inflammatory response of macrophages in infection. Hepatobiliary Pancreat Dis Int 13, 138-152.

Zhao, Z., Wu, L., Xie, J., Feng, Y., Tian, J., He, X., Li, B., Wang, L., Wang, X., Zhang, Y., et al. (2020). Rhodomyrtus tomentosa (Aiton.): A review of phytochemistry, pharmacology and industrial applications research progress. Food Chem 309, 125715.

Zhong, T., Zhang, L.Y., Wang, Z.Y., Wang, Y., Song, F.M., Zhang, Y.H., and Yu, J.H. (2017). Rheum emodin inhibits enterovirus 71 viral replication and affects the host cell cycle environment. Acta Pharmacol Sin 38, 392-401.

Zhou, J., Xu, R., Du, X.Z., Zhou, X.D., and Li, Q. (2017). Saxifragifolin D attenuates phagosome maturation arrest in Mycobacterium tuberculosisinfected macrophages via an AMPK and VPS34-dependent pathway. AMB Expr 7, 11.

Zhu, K., Cordeiro, M.L., Atienza, J., Robinson Jr, W.E., and Chow, S.A. (1999). Irreversible inhibition of human immunodeficiency virus type 1 integrase by dicaffeoylquinic acids. J Virol 73, 3309-3316.

Zuo, G.Y., Zhang, X.J., Yang, C.X., Han, J., Wang, G.C., and Bian, Z.Q. (2012). Evaluation of traditional Chinese medicinal plants for antiMRSA activity with reference to the treatment record of infectious diseases. Molecules 17, 2955-2967.

Zuzarte, M., Gonçalves, M.J., Cavaleiro, C., Canhoto, J., Vale-Silva, L., Silva, M.J., Pinto, E., and Salgueiro, L. (2011). Chemical composition and antifungal activity of the essential oils of Lavandula viridis L'Hér. J Med Microbiol 60, 612-618.

\section{SUPPORTING INFORMATION}

The supporting information is available online at https://doi.org/10.1007/s11427-020-1959-5. The supporting materials are published as submitted, without typesetting or editing. The responsibility for scientific accuracy and content remains entirely with the authors. 